\title{
Cryptococcus and Phagocytes: Complex Interactions that Influence Disease Outcome
}

\author{
Chrissy M. Leopold Wager ${ }^{1,2}$, Camaron R. Hole ${ }^{1,2}$, Karen L. Wozniak ${ }^{1,2}$ and \\ Floyd L. Wormley Jr. 1,2* \\ ${ }^{1}$ Department of Biology, The University of Texas at San Antonio, San Antonio, TX, USA, ${ }^{2}$ The South Texas Center for \\ Emerging Infectious Diseases, The University of Texas at San Antonio, San Antonio, TX, USA
}

Cryptococcus neoformans and C. gattii are fungal pathogens that cause life-threatening disease. These fungi commonly enter their host via inhalation into the lungs where they encounter resident phagocytes, including macrophages and dendritic cells, whose response has a pronounced impact on the outcome of disease. Cryptococcus has complex interactions with the resident and infiltrating innate immune cells that, ideally, result in destruction of the yeast. These phagocytic cells have pattern recognition receptors that allow recognition of specific cryptococcal cell wall and capsule components. However, Cryptococcus possesses several virulence factors including a

OPEN ACCESS

Edited by: Hector Mora Montes, Universidad de Guanajuato, Mexico

Reviewed by:

Alexander Idnurm, University of Melbourne, Australia

Radames J. B. Cordero, Johns Hopkins Bloomberg School of Public Health, USA

*Correspondence:

Floyd L. Wormley

floyd.wormley@utsa.edu

Specialty section: This article was submitted to Fungi and Their Interactions, a section of the journal

Frontiers in Microbiology

Received: 01 December 2015

Accepted: 19 January 2016

Published: 09 February 2016

Citation:

Leopold Wager CM, Hole CR, Wozniak KL and Wormley FL Jr.

(2016) Cryptococcus

and Phagocytes: Complex Interactions that Influence Disease Outcome. Front. Microbiol. 7:105. doi: 10.3389/fmicb.2016.00105 polysaccharide capsule, melanin production and secretion of various enzymes that aid in evasion of the immune system or enhance its ability to thrive within the phagocyte. This review focuses on the intricate interactions between the cryptococci and innate phagocytic cells including discussion of manipulation and evasion strategies used by Cryptococcus, anti-cryptococcal responses by the phagocytes and approaches for targeting phagocytes for the development of novel immunotherapeutics.

Keywords: cryptococcosis, Cryptococcus neoformans, Cryptococcus gattii, Cryptococcus, fungal immunity, innate immune response, medical mycology

\section{Cryptococcus neoformans AND C. gattii}

Cryptococcosis is a disease predominantly caused by the species Cryptococcus neoformans and C. gattii in humans and other mammals (Kwon-Chung et al., 2014). Cryptococcus sp. are generally encountered in the environment. C. gattii is commonly found in tropical and subtropical regions, however, the species is expanding its reach as evidenced by the recent outbreak in Vancouver Island, British Columbia, Canada and the Pacific Northwest of the United States (reviewed in Hole and Wormley, 2012; Kwon-Chung et al., 2014). Until recently, Cryptococcus sp. have been categorized into only these two species and subcategorized by serotype (A-D) and molecular type (VNI-VNIV, and VGI-VGIV; reviewed in Kwon-Chung et al., 2014). Currently, seven species of C. gattii/C. neoformans have been identified based on genotyping studies that have revealed significant genetic diversity within the species complex (Hagen et al., 2015). For the purposes of this review to ensure accurate reference to strains used in the discussed studies, we will refer to the organisms based on their previous C. neoformans (serotype A and D) and C. gattii (serotype B and C) nomenclature unless otherwise specified.

Interestingly, despite sharing 80-90\% genomic identity (Kavanaugh et al., 2006), C. neoformans and C. gattii affect different patient populations and with different disease manifestations. The 
infectious propagule of both species is inhaled into the lungs and the infection is often controlled by the host's immune system (Park and Mehrad, 2009). C. neoformans, however, predominantly causes disease in immunocompromised individuals, including AIDS patients and those undergoing immunosuppressive therapies, resulting in pneumonia and has a predilection to disseminate to the central nervous system (CNS) leading to life threatening meningoencephalitis (Powderly, 1993; van der Horst et al., 1997; Saag et al., 2000; Husain et al., 2001; Liu et al., 2012; Kwon-Chung et al., 2014; Sorrell et al., 2015). C. gattii principally causes disease in healthy individuals with no discernable underlying condition (Marr et al., 2012; Lizarazo et al., 2014). However, the idea that C. gattii is a primary pathogen is being questioned as anti-granulocyte-macrophage colony-stimulating factor (GM-CSF) autoantibodies have been detected in C. gattii infected patients but not in samples from healthy donors (Saijo et al., 2014; Kwon-Chung and Saijo, 2015). Thus, anti-GM-CSF autoantibodies could indicate an underlying immunodeficiency that predisposes patients to C. gattii infection. This demonstrates a need for more comprehensive screening before classifying a patient as "immunocompetent" and further examination of the C. gattii patient population. Another striking difference between these two species is that $C$. gattii shows little penchant for dissemination to the CNS compared to C. neoformans (Ngamskulrungroj et al., 2012). Comparison of two virulent strains of C. neoformans (strain H99) and C. gattii (strain R265) revealed that even though C. gattii can cross the blood-brain barrier (BBB), C. neoformans grew 10-100 times faster in naïve mouse blood and serum (Ngamskulrungroj et al., 2012). This suggests that these two species have a different specificity for their target organ that is not yet fully elucidated.

\section{IMMUNE RESPONSE}

The host has efficient mechanisms for combating these debilitating fungi. Initiation of a pro-inflammatory Th1-type immune response, characterized by interleukin-2 (IL-2), IL12, IL-18, interferon- $\gamma($ IFN- $\gamma)$ and tumor necrosis factor- $\alpha$ (TNF- $\alpha$ ), is protective against Cryptococcus (Huffnagle et al., 1991; Aguirre et al., 1995; Huffnagle, 1996; Kawakami et al., 1996, 1997a; Zhang et al., 1997, 2009; Huffnagle and Lipscomb, 1998; Olszewski et al., 2010). Additionally, generation of an anti-inflammatory Th2-type immune response, characterized by IL-4, IL-5, IL-13, and the immunoregulatory cytokine IL-10, is associated with exacerbation of disease (Huffnagle et al., 1998; Arora et al., 2005, 2011; Milam et al., 2007; Muller et al., 2007; Chen et al., 2008; Jain et al., 2009; Osterholzer et al., 2009b). In addition, a Th17-type response characterized by IL-17A, IL-21, IL-22, IL-6, and TGF- $\beta$ (Korn et al., 2007, 2009; Onishi and Gaffen, 2010) has been shown to contribute to anti-cryptococcal immune responses (Zhang et al., 2009; Murdock et al., 2014). However, IL-17A and signaling through the IL-17A receptor is not required for clearance in a protective model of cryptococcosis (Wozniak et al., 2011a).
Experimental studies in mice with certain C. neoformans strains, including the highly virulent strain $\mathrm{H} 99$, results in a Th2-type polarized response which is not protective (Huffnagle et al., 1998; Milam et al., 2007; Muller et al., 2007; Chen et al., 2008; Xiao et al., 2008; Osterholzer et al., 2009b). However, studies using a C. neoformans strain H99 that was genetically engineered to express and secrete murine IFN- $\gamma$

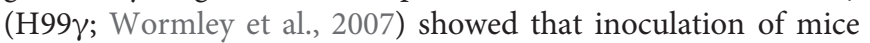
with strain $\mathrm{H} 99 \gamma$ results in protective Th1-type responses and IL17 production, increased leukocyte infiltration and production of pro-inflammatory cytokines/chemokines (Wormley et al., 2007; Wozniak et al., 2009, 2011a). In addition, immunization of mice with $\mathrm{H} 99 \gamma$ yields $100 \%$ protection against subsequent challenge with WT C. neoformans H99, providing evidence that vaccination against C. neoformans is possible (Wormley et al., 2007; Wozniak et al., 2009; Hardison et al., 2010, 2012). Furthermore, studies examining $\mathrm{T}$ cell depleted mice showed that mice immunized with $\mathrm{H} 99 \gamma$ and challenged with WT C. neoformans during T cell depletion were also protected against challenge, showing that immune-compromised hosts could be protected (Wozniak et al., 2011b). The majority of studies utilize C. neoformans as a model organism to assess protection via Th1 and Th17-type responses, however, several studies have suggested that protection against C. gattii employs a different mechanism. It has been shown that infection with C. gattii leads to suppression of host's immune responses, including decreased leukocyte recruitment and proinflammatory cytokine production (Dong and Murphy, 1995; Wright et al., 2002; Cheng et al., 2009). This could provide an indication as to how C. gattii is able to affect immunocompetent individuals, while C. neoformans predominantly causes disease in the immunocompromised populations.

It is crucial that the host immune responses will eradicate or limit the spread of fungal pathogens from the lung before they are able to disseminate. The host relies on pulmonary innate immune cells as its first line of defense against Cryptococcus sp. These include the phagocytic macrophages, dendritic cells (DCs) and neutrophils. When the yeast-like cell or basidiospore is encountered by the phagocyte, the phagocytic cell will engulf the invading organism forming a phagosome. Ideally, the phagosome will mature, acidify following fusion with a lysosome (forming the phagolysosome), and lead to the destruction of the fungus. Cryptococcus sp. have evolved a number of defense mechanisms and virulence factors that allow it to either survive in the phagosome or avoid phagocytosis altogether (reviewed in Kronstad et al., 2011; Kwon-Chung et al., 2014; Alspaugh, 2015). The capsule of Cryptococcus is a complex and elaborate structure composed of glucuronoxylomannan (GXM), galactoxylomannan (GalXM) and, to a lesser degree, mannoproteins and is anchored to the cell wall, which is composed of chitin, chitosan (acetylated chitin), glucans and glycoprotein (Doering, 2009; O'Meara and Alspaugh, 2012). The capsule is dynamic and dramatically increases in thickness during infection or when cultured in host inducing conditions (RPMI, $37^{\circ} \mathrm{C}$ ). Additionally, the capsule functions to mask cryptococcal pathogen associated molecular patterns (PAMPs) that can be recognized by pattern recognition receptors (PRRs) on host cells, allowing Cryptococcus to evade the immune system by preventing phagocytosis and can aid 
in providing protection against reactive oxygen species and antimicrobial peptides (Zaragoza et al., 2008). Opsonization of Cryptococcus with anti-capsular antibodies is required for phagocytosis by immune cells due to the anti-phagocytic properties of the capsule (reviewed in Kozel, 1993). The ability to form "titan cells" is another anti-phagocytic mechanism utilized by Cryptococcus. In the pulmonary environment, C. neoformans cells can attain a large cell size varying from 50 to $100 \mu \mathrm{m}$ in diameter with varying degrees of capsule thickness making them resistant to phagocytosis (Okagaki et al., 2010; Zaragoza et al., 2010; Okagaki and Nielsen, 2012). Melanin production by laccase is another virulence factor of C. neoformans and C. gattii which serves to protect the organism from oxidative stresses within the phagolysosome by breaking down host substrates into reactive intermediates that can harm the host (Zhu and Williamson, 2004; Panepinto and Williamson, 2006). One example of this is the iron oxidase activity of laccase in the phagolysosome that reduces potentially toxic Fenton reactants, thus protecting Cryptococcus from the antifungal activity of alveolar macrophages (Liu et al., 1999). Other virulence factors include the ability to grow and proliferate at mammalian body temperature $\left(37^{\circ} \mathrm{C}\right)$ and extracellular enzymes including laccases, urease, and phospholipases (reviewed in Kronstad et al., 2011; Almeida et al., 2015). In this review, we discuss interactions between Cryptococcus sp. and innate phagocytic cells and how these interactions determine the outcome of disease.

\section{MACROPHAGES}

\section{Macrophage Activation}

Resident alveolar macrophages which live within the lung alveolar airspaces are critical to host defense as the first line of defense against pulmonary pathogens (Fels and Cohn, 1986). Alveolar and infiltrating macrophages phagocytose and kill invading pathogens and are capable of presenting antigen to activated $\mathrm{T}$ cells to stimulate an adaptive immune response in immunocompetent individuals. Interestingly, macrophages have a dynamic plasticity which allows them to respond to changes in their cytokine microenvironment and alter their activation phenotype (Porcheray et al., 2005; Stout et al., 2005; Gratchev et al., 2006; Sica and Mantovani, 2012; Davis et al., 2013; Mantovani et al., 2013; Leopold Wager and Wormley, 2014). Macrophage activation phenotype is broadly classified as classical (M1) or alternative (M2) based on cytokine production, extracellular receptor expression and secreted byproducts (Stout and Suttles, 2004; Mosser and Edwards, 2008; Sica and Mantovani, 2012). Immune cells, including natural killer (NK) cells, CD8 ${ }^{+} \mathrm{T}$ cells, and $\mathrm{CD}^{+}{ }^{+}$T-helper 1 (Th1)type cells (Mosser and Edwards, 2008) respond to the pathogen by secreting inflammatory cytokines, including IFN- $\gamma$ which signals macrophages to polarize toward an M1 phenotype (Mantovani et al., 2004; Mosser and Edwards, 2008; Martinez et al., 2009; Hussell and Bell, 2014). The markers commonly used for identification of M1 macrophages include inducible nitric oxide synthase (iNOS), chemokine (C-X-C motif) ligand 9 (CXCL9), CXCL10, CXCL11, IL-12, and suppressor of cytokine signaling 3 (SOCS3; reviewed in Mosser and Edwards, 2008; Murray and Wynn, 2011; Leopold Wager and Wormley, 2014). M1 macrophages mediate host defense against microbial pathogens via the generation of reactive oxygen and nitrogen species (ROS and RNS, respectively; Ding et al., 1988). The enzyme iNOS acts on the substrate L-arginine to produce nitric oxide (NO), which has anti-cryptococcal properties (Figure 1; Alspaugh and Granger, 1991; Arora et al., 2011; Hardison et al., 2012; Davis et al., 2013; Leopold Wager et al., 2014, 2015). Conversely, the enzyme arginase-1 (Arg-1) is a hallmark marker of M2 macrophage activation and competes with iNOS for this substrate producing L-ornithine and urea (Bogdan et al., 2000). The Arg1 to iNOS ratio is often considered an indicator of macrophage polarization phenotype as conditions leading to the induction of M2 macrophages inhibit M1 macrophage activation (Takeda et al., 1996; Van Dyken and Locksley, 2013).

The induction of M2 macrophage activation is mediated by cytokines including IL-4 and IL-13 (Mosser and Edwards, 2008; Mantovani et al., 2013; Van Dyken and Locksley, 2013). It was recently shown that cryptococcal Ssa1, a heat shock protein 70 homolog, is secreted by C. neoformans and promotes early fungal growth and a shift to M2 macrophage activation by stimulating early production of IL-4 and IL-13 (Eastman et al., 2015). M2 macrophages contribute to the suppression and regulation of inflammatory responses and play a pivotal role in wound-healing, but are not antimicrobial against C. neoformans (Arora et al., 2005, 2011; Mosser and Edwards, 2008; Martinez et al., 2009; Hardison et al., 2010, 2012; Murray and Wynn, 2011; Davis et al., 2013; Van Dyken and Locksley, 2013; Leopold Wager and Wormley, 2014; Leopold Wager et al., 2014, 2015). C. neoformans cells can survive in M2 macrophages by using them as a protective niche to evade recognition and killing by the host (reviewed in Johnston and May, 2013). Immune cells including Th2-type $\mathrm{CD}^{+} \mathrm{T}$ cells, basophils, eosinophils, mast cells and group 2 innate lymphoid cells (ILC2s) are sources of IL-4 and/or IL13 (Martinez et al., 2009; Murray and Wynn, 2011; Walker and McKenzie, 2013; Walker et al., 2013). Recently, it was shown that chitin, an integral part of the cryptococcal cell wall, indirectly stimulates the production of IL-5 and IL-13 and can trigger IL-4 production, resulting in M2 macrophage activation (Reese et al., 2007; Van Dyken et al., 2014). IL-4 can stimulate increased expression of mannose receptor (MR or CD206), the first described M2 macrophage activation-associated marker (Stein et al., 1992). The commonly associated markers of M2 macrophage activation also include arginase1 (Arg1), found in inflammatory zone 1 (FIZZ1, also known as resistin-like $\alpha$ or Relm- $\alpha$ ), and chitinase and chitinase-like molecules such as YM1 (Chi313) and YM2 (Mosser and Edwards, 2008; Murray and Wynn, 2011).

Interestingly, macrophages, which are polarized toward an M1 phenotype in the presence of IFN- $\gamma$, can re-polarize to an M2 phenotype when stimulated with IL-4. Similarly, M2 polarized macrophages can re-polarize toward a functional M1 phenotype in the presence of IFN- $\gamma$ and are able to maintain functional anti-cryptococcal activity (Stout et al., 2005; Gratchev et al., 2006; Davis et al., 2013), signifying the critical importance of 


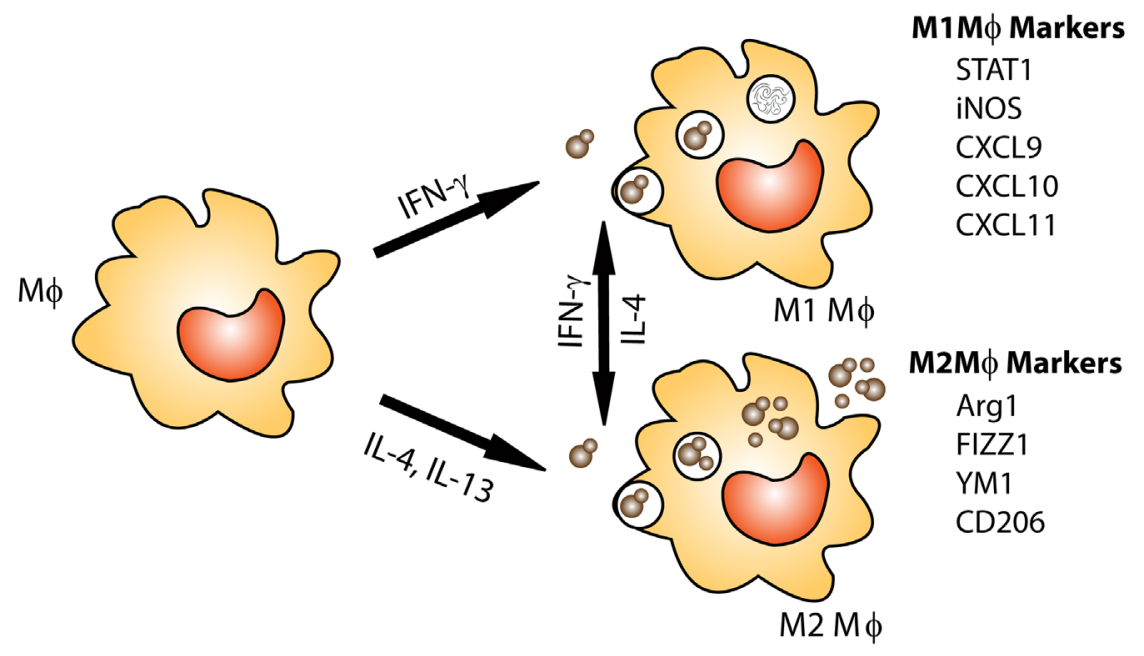

FIGURE 1 | Macrophage activation: protection against Cryptococcus is associated with M1 or classically activated macrophages. M1 macrophages are induced by exposure to the Th1 cytokine IFN- $\gamma$. M1 macrophages are efficient killers as they have increased nitric oxide (NO) and ROS production. M2 or alternatively activated macrophages are associated non-protective immune responses to Cryptococcus. M2 macrophages are not efficient killers and allow Cryptococcus to grow and proliferate within the macrophage and may lead to dissemination. In addition, macrophage phenotype is plastic, allowing for macrophages to switch between M1 and M2 phenotypes based on cytokines present in their environment.

the local cytokine milieu in driving macrophage polarization. IFN- $\gamma$ production by Th1-type T cells and NK cells can stimulate M1 macrophage activation in a signal transducer and activator of transcription (STAT) 1-dependent manner (Hu et al., 2002). Studies utilizing the IFN- $\gamma$ producing $C$. neoformans strain have illustrated that STAT1 signaling in macrophages is required for M1 macrophage activation and protection (Leopold Wager et al., 2014; Leopold Wager et al., 2015). More in-depth discussion of the macrophage polarization and C. neoformans infections has been recently published elsewhere (Leopold Wager and Wormley, 2014). Conversely, a clinical study recently showed that despite elevated IFN- $\gamma$ levels and pro-inflammatory factors in the brains of two non-HIV cryptococcal meningitis patients, poor phagocytosis and macrophages polarized to the nonprotective M2 phenotype was observed (Panackal et al., 2015). This establishes that macrophage polarization in response to C. neoformans in humans is quite complex and requires further study.

Cryptococcus neoformans is sensitive to the NO produced by M1 macrophages (Alspaugh and Granger, 1991; Aguirre and Gibson, 2000; Rivera et al., 2002; Muller et al., 2007; Osterholzer et al., 2009b; Stenzel et al., 2009; Zhang et al., 2009; Hardison et al., 2010). C. neoformans is thought to down-regulate macrophage iNOS RNA, thus mediating NO suppression (Kawakami et al., 1997b; Chinen et al., 1999). Inhibition of iNOS results in M2 macrophage activation, loss of anti-cryptococcal activity and progression of disease (Naslund et al., 1995; Arora et al., 2005, 2011; Xiao et al., 2008; Hardison et al., 2010; Leopold Wager et al., 2015). In addition, macrophages from iNOS deficient mice or from WT mice cultured with iNOS inhibitors are unable to control the intracellular proliferation of C. neoformans, even in the presence of intact ROS production (Leopold Wager et al., 2015). This reveals that NO, and not ROS, is the mechanism used by M1 macrophages to control C. neoformans in mice. However, how well this finding translates to human macrophages is a point of contention as the human iNOS gene is generally epigenetically silenced by CpG methylation, histone modifications and chromatin compaction (Gross et al., 2014). Interestingly, other studies have shown granulomas from pulmonary tissues in humans and non-human primates contain iNOS $^{+}$macrophages (Facchetti et al., 1999; Mattila et al., 2013), suggesting that human macrophages are capable of NO production that could control cryptococcal growth. Further studies that would characterize the human macrophage response to Cryptococcus are required to comprehensively address this question.

\section{Survival and Replication in Macrophages}

Following phagocytosis, cryptococci have been shown to proliferate in the macrophage phagosome (Tucker and Casadevall, 2002; Voelz et al., 2009), suggesting that these phagocytes are a preferred niche of the yeast where it can hide from recognition by the host's immune system (Johnston and May, 2013). A clinical study recently examined 65 clinical isolates of $C$. neoformans and demonstrated that strains with high rates of phagocytosis by macrophages with low intracellular proliferation in vitro coincided with higher CSF fungal burdens and, paradoxically, long-term survival of HIV patients (Sabiiti et al., 2014). The strains with high uptake rates were hypocapsular, had enhanced laccase activity, and were more resistant to patient antifungal treatment (Sabiiti et al., 2014). This study demonstrates that cryptococcal-phagocyte interactions are a major contribution to human clinical presentation and outcome.

In the phagosome, cryptococci are exposed to low $\mathrm{pH}$, ROS and NO. Studies have shown that C. neoformans does not actively avoid acidification of the phagolysosome in macrophages, 
but actually proliferate better in acidic rather than alkaline conditions (Diamond and Bennett, 1973; Levitz et al., 1999). Interestingly, live, but not heat killed, $C$. neoformans can induce premature removal of phagosome markers Rab5 and Rab11 (early phagosome markers; Smith et al., 2015). In contrast to previous studies, Smith et al. (2015) have recently shown that $C$. neoformans can hinder significant acidification of the phagosome, calcium flux and protease activity, rendering the phagosome permissive to cryptococcal proliferation in both the J774.1 macrophage-like cell line and human monocyte derived macrophages. This study also demonstrated that several virulence attenuated mutants are able to prevent phagosome maturation (Smith et al., 2015), suggesting that an unknown mechanism regulates this process. Studies have shown that incubation of murine macrophages with $C$. neoformans can result in host damage via activation of stress pathway including HIF- $1 \alpha$, receptor-interacting protein 1 , apoptosis-inducing factor and mitochondrial depolarization (Coelho et al., 2015). A recent study by Davis et al. (2015) showed that live C. neoformans can cause lysosomal damage in bone marrow derived macrophages (BMM) which increases over time (Davis et al., 2015). Stimulation of BMMs with IFN- $\gamma$ negated the lysosomal damage and increased killing of the yeast (Davis et al., 2015), suggesting that the induction of lysosomal damage is a potential survival strategy of $C$. neoformans that is counteracted when macrophages are activated to the M1 phenotype.

Phospholipase B, a known virulence factor of Cryptococcus, is a phospholipid modifying enzyme found at the cell surface (Djordjevic et al., 2005). This enzyme is active under acidic conditions at $37^{\circ} \mathrm{C}$, as found in macrophage lysosomes. Deletion of PLB1 in C. neoformans results in attenuated virulence, increased capsular diameter and size in the phagosome and in the lung (Evans et al., 2015). PLB1 is also required for proliferation and survival in macrophages, as well as for dissemination to the CNS (Evans et al., 2015). Another cryptococcal protein, Fbp1, is critical for survival and proliferation in the macrophage phagosome and for dissemination from the lungs (Liu and Xue, 2014). Fbp1, along with its substrate inositol phosphosphingolipid-phospholipase $\mathrm{C}$, is required for resistance to NO and dissemination (Liu and Xue, 2014).

Cryptococcus neoformans is capable of surviving even in a phagosome with ROS, in part due to absorption of ROS by the capsule (Zaragoza et al., 2008). In addition, the plasma membrane high-affinity Cch1-Mid1 calcium channel (CMC) of C. neoformans promotes cryptococcal survival during exposure to oxidative stress (Vu et al., 2015). Cch1 mutants have decreased survival in J774.1A macrophages, however, C. neoformans deficient in both Cch1 and Mid1 maintain resistance to the ROS, suggesting a compensatory mechanism in the yeast (Vu et al., 2015). C. gattii, however, has been shown to use a novel mechanism in response to ROS. The C. gattii Vancouver Island outbreak strain R265 induces to tubularization of its mitochondria, which can facilitate the growth of nearby "normal" C. gattii cells (Voelz et al., 2014). This enables the cryptococci to establish an intracellular niche in the macrophage, increasing pathogenesis. There was no observed correlation in C. neoformans between mitochondria tubularization and intracellular proliferation rate (Voelz et al., 2014), suggesting a unique mechanism of C. gattii.

\section{Trafficking Through the Blood Brain Barrier}

Remarkably, C. neoformans is capable of non-lytic exocytosis, where the yeast cells burst out of the macrophage without lysing the phagocyte, again, preventing a response from the host (Alvarez and Casadevall, 2006; Johnston and May, 2010; Nicola et al., 2011). The ability of Cryptococcus to proliferate inside macrophages and then escape is the basis for one hypothesis as to how $C$. neoformans traffics across the BBB to cause meningoencephalitis in immunocompromised hosts. It has been posited that macrophages act as a "Trojan horse" carrying the yeast-like cells into the CNS while hidden from the immune system (Liu et al., 2012). Histological sections of C. neoformans infected brain tissue show cryptococci within macrophage-like cells either within or outside capillaries (Chretien et al., 2002). A second hypothesis is paracellular crossing of the $\mathrm{BBB}$ due to loss of integrity in the tight junctions or injury to the brain endothelium. These events compromise the BBB, leaving openings for the yeast cells to cross into the CNS (Ibrahim et al., 1995; Chen et al., 2003; Olszewski et al., 2004; Charlier et al., 2005). Third, the transcellular pathway is a hypothesis in which cryptococcal cells transmigrate via adherence to and internalization by the brain endothelium from the luminal surface (blood side) to the abluminal side (brain side) of the BBB (Chang et al., 2004; Liu et al., 2012; Sabiiti and May, 2012). The metalloprotease Mpr1 of C. neoformans is an extracellular protein that is required for migration across the $\mathrm{BBB}$ as it promotes adherence of the yeast cells to the brain endothelial cells (Vu et al., 2014). C. neoformans deficient in Mpr1 is able to survive in J774.1 macrophages (Vu et al., 2014), providing additional evidence for the transcellular pathway hypothesis.

Murine studies suggest that C. gattii does not traffic to the brain as readily as C. neoformans (Ngamskulrungroj et al., 2012), suggesting that dissemination to the CNS is not a primary target of C. gattii. C. neoformans is phagocytosed more efficiently by THP-1 macrophage-like human cells regardless of prior stimulation of the macrophage-like cells with IFN- $\gamma$ (Sorrell et al., 2015). Remarkably, more C. neoformans-loaded macrophages traveled across the human brain endothelial cell line monolayer (a model of the BBB) than C. gattii-loaded macrophages (Sorrell et al., 2015). C. neoformans also had a higher rate of expulsion from the THP-1 macrophages (Sorrell et al., 2015), further validating the Trojan horse hypothesis. All hypotheses concerning trafficking of $C$. neoformans to the CNS are supported by strong evidence as discussed above. A likely explanation is that all mechanisms of trafficking are utilized by C. neoformans to gain access to this privileged site.

\section{DENDRITIC CELLS}

Dendritic cells are innate cells that act as sentinels of the immune system. These cells are phagocytes, but also have the ability to present antigen to naïve $\mathrm{T}$ cells in order to direct 
the adaptive immune response. Initial in vitro studies of DCs with $C$. neoformans showed that DCs are involved in detection, binding, phagocytosis, processing, antigen presentation, $\mathrm{T}$ cell activation, and killing of the organism (Bauman et al., 2000, 2003; Wozniak et al., 2006; Wozniak and Levitz, 2008). Early studies showed that Langerhans cells and myeloid DCs are necessary for the induction of protective immune responses against C. neoformans (Bauman et al., 2000).

Uptake of C. neoformans by DCs requires opsonization with either anti-capsular antibody or complement, due to the antiphagocytic polysaccharide capsule surrounding the cryptococcal organisms (Kelly et al., 2005). In contrast to encapsulated strains, phagocytosis of acapsular mutant $C$. neoformans strains by DCs requires MR and Fc $\gamma R$ II (Syme et al., 2002). Toll-like receptor 2 (TLR2) and TLR4 are not important in uptake of C. neoformans or activation of DCs by the fungus (Nakamura et al., 2006). Following phagocytosis by DCs, cryptococci translocate to the endosomal compartment followed by the lysosomal compartment, where they are killed by oxidative and non-oxidative mechanisms (Kelly et al., 2005; ArtavanisTsakonas et al., 2006; Wozniak and Levitz, 2008; Hole et al., 2012). Studies examining DC lysosomal extract in vitro showed direct anti-cryptococcal activity (Wozniak and Levitz, 2008; Hole et al., 2012). Purified lysosomal enzymes, specifically cathepsin $\mathrm{B}$, inhibit cryptococcal growth by cell wall damage followed by osmotic lysis of the cryptococcal cells (Hole et al., 2012).

During a cryptococcal infection in a mouse model, cryptococci are rapidly internalized by pulmonary DCs (Wozniak et al., 2006). These DCs increase surface expression of costimulatory molecules CD80 and CD86 as well as MHC II by D7 postinfection. DCs isolated from infected lungs present cryptococcal mannoprotein (MP) to MP-specific $\mathrm{T}$ cells and induced $\mathrm{T}$ cell activation and proliferation ex vivo (Wozniak et al., 2006). Furthermore, DC phagocytosis of cryptococcal MP in the presence of the appropriate adjuvant, such as the Th1-type inducing adjuvant $\mathrm{CpG}$, induces production of protective Th1type cytokines (Mansour et al., 2002; Dan et al., 2008a). Upon uptake of cryptococcal MP, DCs express markers of activation and maturation including MHC I and MHC II as well as CD40, CD80, and CD86 (Pietrella et al., 2005; Dan et al., 2008a,b). MP induces human DCs to secrete IL-12 and TNF- $\alpha$, which are associated with the protective Th1-type immune response, and also leads to Iк $\beta \alpha$ phosphorylation (Pietrella et al., 2005). MP-loaded DCs are efficient stimulators of $\mathrm{T}$ cells resulting in CD4 and CD8 proliferation (Pietrella et al., 2005). Additional studies revealed that the interaction of $C$. neoformans with DCs, but not macrophages, induced the production of IL-12 and IL-23, two cytokines associated with protection against cryptococcosis (Kleinschek et al., 2010). Though macrophages are capable of presenting antigen to activated $\mathrm{T}$ cells, it is the DCs that are the most efficient antigen presenting cell type to present C. neoformans mitogen, and only a small number of DCs are needed for antigen presentation to T cells (Syme et al., 2002).

Dendritic cells and alveolar macrophages are required for protection against cryptococcal infection and are needed early in host defense (Osterholzer et al., 2009a). Depletion of DCs abrogated the $\mathrm{T}$ cell response in mice (Mansour et al., 2006). Depletion of $\mathrm{CD}_{11 c^{+}}$cells using a CD11cDTR mouse during cryptococcal infection lead to mortality within 6 days post-infection. Death was associated with neutrophilic bronchopneumonia and alveolar damage (Osterholzer et al., 2009a). The recruitment of monocyte-derived DCs into the lung appears to be dependent on the chemokine receptor CCR2. CCR2 KO mice infected with C. neoformans show impaired DC recruitment and the mice developed features of a Th2-type response including persistent infection, bronchovascular collagen deposition, and increased IL4 production (Osterholzer et al., 2008). CCR2-dependent recruitment of DCs into C. neoformans infected lungs was due to increased recruitment of Ly-6 $\mathrm{C}^{\text {high }}$ monocytes that differentiate into $\mathrm{CD}_{11 \mathrm{~b}}^{+}$DCs in the lungs (Osterholzer et al., 2009a). These data suggest that CCR2 is required for the recruitment of DCs to the lungs and initiation of protective immune responses during a cryptococcal infection. (Osterholzer et al., 2008).

Cryptococcal capsule prevents phagocytosis of the organism (in the absence of opsonization by complement or antibody). In addition to its role in preventing phagocytosis by DCs and other phagocytes, the main capsular polysaccharide, GXM, has profound suppressive effects on immune responses (Yauch et al., 2006; Zaragoza et al., 2009). Cryptococcal capsule interferes with both DC activation and maturation (Vecchiarelli et al., 2003; Lupo et al., 2008; Grijpstra et al., 2009). In contrast, acapsular strains phagocytosed by DCs induce surface expression of MHC II and other costimulatory molecules, whereas the encapsulated strains do not induce activation unless opsonized by an anti-GXM antibody which is recognized by CD32 and CD16 (Vecchiarelli et al., 2003). Acapsular mutant strain cap56 $\Delta$ induces human DC activation as seen by increased CD80 and CD86 surface expression (Grijpstra et al., 2009). In addition to affecting DC maturation, capsular material can influence DC gene expression of several cytokines and chemokines associated with protective responses as well as genes associated with antigen presentation (Lupo et al., 2008). Encapsulated strains induce a down-regulation of cytokine genes and inhibited the induction of the genes for cytokine and chemokine production as well as antigen presentation (Lupo et al., 2008).

Although the Th1-type immune response is typically associated with protective anti-cryptococcal responses, a Th2type response may not always be detrimental under certain conditions. Experimental pulmonary infection of IL- $4 \mathrm{R} \alpha \mathrm{KO}$ mice with a $C$. neoformans serotype $\mathrm{D}$ strain resulted in higher fungal burden compared to WT mice (Grahnert et al., 2014). Additionally, IL-4R $\alpha$ KO mice exhibited a defect in DC and macrophage recruitment due to a reduction in CCL2 and CCL20 chemokines. There was also a reduction in IFN- $\gamma$ and NO production in the IL-4R $\alpha$ KO mice (Grahnert et al., 2014). In vitro culture of DCs in the presence of C. neoformans and IL-4 resulted in increased IL-12 and reduced IL-10 production by the DCs (Grahnert et al., 2014). These data in conjunction with the increased fungal burden in the IL- $4 \mathrm{R} \alpha \mathrm{KO}$ mice suggest a beneficial role of IL-4R $\alpha$ signaling early during infection, whereas 
IL-4R $\alpha$ signaling during the late phase of infection is detrimental (Grahnert et al., 2014).

Infection with virulent wild-type C. neoformans strains naturally induce a strong Th2-type immune response. Urease produced by $C$. neoformans directed a strong Th2-type immune response and lead to a significant increase in the amount of immature DCs that accumulated in the lung-associated lymph nodes (Osterholzer et al., 2009b). Using a tetramer for chitin deacetylase 2 (CDA2), Wiesner et al. (2015) were able to isolate Cryptococcus-specific Th2 $\mathrm{CD}^{+}{ }^{+} \mathrm{T}$ cells and found that chitin recognition via chitotriosidase leads to the induction of Th2 cells by DCs. Using multiple DC KO and DC depleted mouse models, Wiesner et al. (2015) also demonstrated that lung-resident $\mathrm{CD}_{11 \mathrm{~b}}{ }^{+}$IRF4-dependent conventional DCs are responsible for the induction of Th2-type T cells. This indicates that DCs can have a protective or a non-protective role in the immune response to C. neoformans. The ability of DCs to react protectively or nonprotectively suggests that these cells are heavily influenced by their environment, a fact that could be exploited for development of novel immunotherapies to combat cryptococcosis.

The interaction of DCs with C. gattii can differ dramatically from C. neoformans. Human monocyte-derived DCs can kill C. gattii, but this does not induce DC maturation (Figure 2; Huston et al., 2013). Even after uptake and processing of C. gattii by human DCs, they do not increase expression of MHC class II, CD86, CD83, CD80, and CCR7, which results in defects in $\mathrm{T}$ cell responses (Huston et al., 2013). In addition, DCs that kill C. gattii do not trigger a release of TNF- $\alpha$, which is important for cryptococcal clearance (Huston et al., 2013). In mice infected with C. gattii, the DCs express much lower levels of surface MHC II and IL-12 or IL-23 transcripts and fail to induce effective Th1 and Th17 differentiation in vitro compared to mice infected with C. neoformans (Angkasekwinai et al., 2014). In a DC vaccine model for C. gattii, uptake of an acapsular mutant by DCs induced expression of costimulatory molecules and inflammatory cytokines (Ueno et al., 2015). Mice immunized intravenously with BMDCs pulsed with this acapsular mutant and challenged with C. gattii R265 showed significantly less pathology, reduced fungal burden, significantly increased survival compared to controls. Immunized mice had significantly increased lung and spleen lymphocytes producing IL-17A, IFN- $\gamma$, and TNF- $\alpha$ compared to non-immunized mice, and protection was significantly reduced IFN $-\gamma \mathrm{KO}$ mice (Ueno et al., 2015). Altogether, prevention of DC maturation by C. gattii could explain how this yeast causes disease in seemingly immunocompetent individuals.

\section{NEUTROPHILS}

Neutrophils are phagocytes that are recruited to the lungs during cryptococcal infection and can kill C. neoformans. However, the importance of neutrophils in protective responses against cryptococcal infection is unclear. Human neutrophils, polymorphonuclear leukocytes (PMNs), have been shown to kill $C$. neoformans in vitro by both oxidative and nonoxidative mechanisms (Mambula et al., 2000). Treatment with inhibitors of the respiratory burst only partially reduced the anticryptococcal activity of human PMNs (Mambula et al., 2000). The non-oxidative anti-cryptococcal activity of human PMNs was shown to be mediated by calprotectin and defensins (Mambula et al., 2000). Mice lacking myeloperoxidase (MPO), an enzyme associated with neutrophil antimicrobial activity, succumb to the infection faster than WT mice upon infection with C. neoformans either intranasally or intravenously (Aratani et al., 2006). In vitro, neutrophils migrate toward cryptococcal cells using the complement C5a-C5aR pathway, and the interaction leads to phagocytosis and killing of $C$. neoformans and enhances activation of Erk and p38 mitogen activated protein kinases (MAPK) in neutrophils (Sun et al., 2016). Interestingly, inhibition of p38 MAPK pathway significantly decreased neutrophil migration and cryptococcal killing (Sun et al., 2016). Further studies showed that neutrophils can migrate into the brain microvasculature, phagocytose the cryptococcal cells before they are able to migrate into the brain parenchyma, and re-enter the circulation, effectively removing the cryptococci from the brain (Zhang et al., 2015b).

While neutrophils can kill C. neoformans, the pathogen can also modulate the neutrophil response. Cryptococcal capsular and cell wall components can inhibit neutrophil migration (Coenjaerts et al., 2001; Ellerbroek et al., 2004) and can inhibit the production of neutrophil extracellular traps (NETs; Rocha et al., 2015). In addition, melanized C. neoformans cells are able to abrogate the killing activity of neutrophils by interfering with sphingomyelin synthase (SMS) activity, which is required for cryptococcal killing by neutrophils (Qureshi et al., 2010, 2011). Cryptococcal cells can prevent neutrophil migration by secreting capsular components, which activates microglia to produce IL-8 (a neutrophil chemoattractant) and also reduces the expression of L-selectin (CD62L) on the neutrophil surface in humans with disseminated cryptococcosis, reducing neutrophil migration. Neutrophil endothelial rolling and production of surface expression of TNF- $\alpha$ receptor are also impaired due to cryptococcal capsular polysaccharide (reviewed in Urban et al., 2006).

Neutrophil depletion in mice during protective immune responses does not affect pulmonary fungal burden, indicating that neutrophils are not required for cryptococcal clearance (Wozniak et al., 2012). These data further support the observation by Mednick et al. (2003) that neutropenic mice given a pulmonary $C$. neoformans infection survived significantly longer than control mice with intact neutrophils, therefore indicating that neutrophils are not necessary for protective responses against cryptococcal infection. Furthermore, the presence of neutrophils in the lungs during cryptococcal infection can cause additional damage to the host (Osterholzer et al., 2009a).

In a rat model of C. gattii infection, there is an early recruitment of neutrophils into the lungs, but phagocytosis of cryptococci is not observed (Wright et al., 2002). C. gattii inhibits or fails to induce migration of neutrophils to the site of infection, thereby impeding an inflammatory response (Cheng et al., 2009). In addition, encapsulated C. gattii environmental strains that produced extracellular fibrils (which may be 


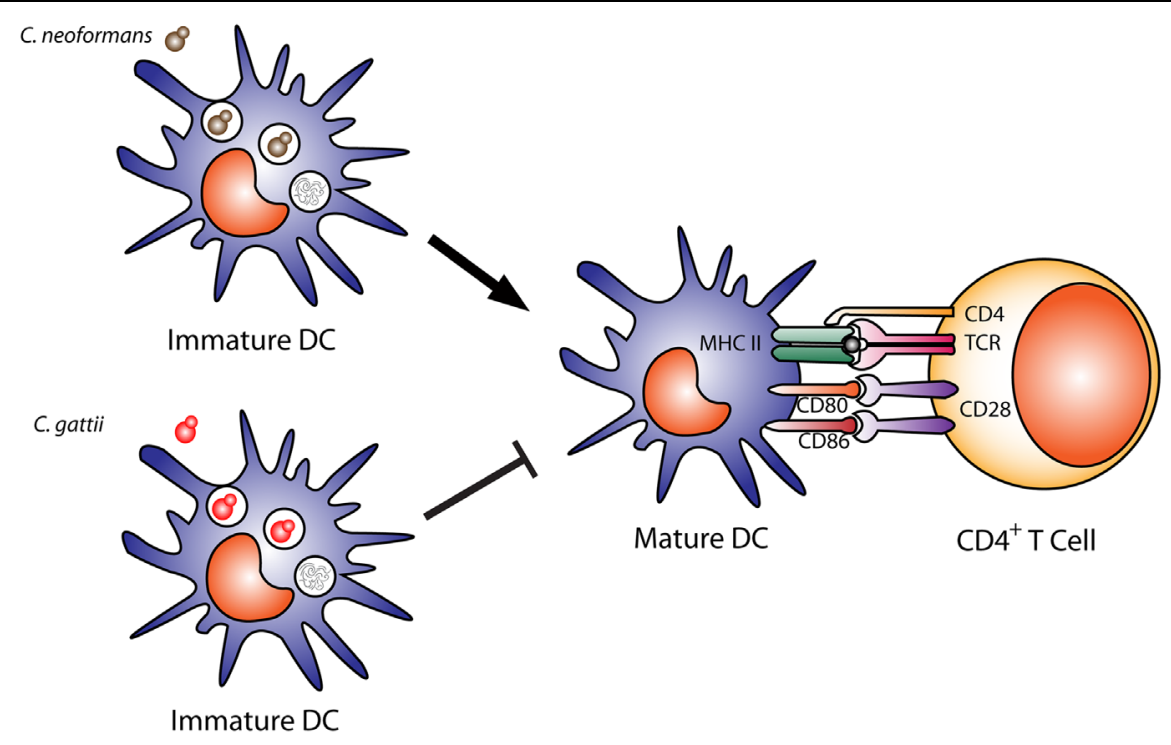

FIGURE 2 | Dendritic cell cryptococcal killing and antigen presentation. Immature dendritic cells efficiently phagocytose and kill opsonized Cryptococcus neoformans cells, leading to DC maturation, shown by upregulation of costimulatory molecules (MHC II, CD80, CD86) and antigen presentation to CD4+ T cells. In contrast, C. gattii can also be phagocytosed and killed by DCs, but leads to a downregulation of DC maturation and expression of costimulatory molecules MHC II, CD80, CD86 and reduces antigen presentation to T cells.

important in cryptococcal cell communication or cryptococcalhost communication) were resistant to neutrophil killing, even when neutrophils produced NETs (Springer et al., 2010).

\section{PATTERN RECOGNITION RECEPTORS}

In order for the phagocytic cell to take up a pathogen, it has to recognize that the pathogen is foreign. The cell does this by recognition of PAMPs via germline-encoded PRRs present either on the cell surface or within distinct intracellular compartments. These PRRs include TLRs, C-type lectin receptors (CLRs), NOD-like receptors and others. PRRs recognize a wide range of bacterial, fungal, and viral PAMPS, including lipopeptides, peptidoglycan, $\beta$-glucans mannan, and pathogen DNA and RNA (Figure 3).

One of the main virulence factors of Cryptococcus is the antiphagocytic polysaccharide capsule (Zaragoza et al., 2009). TLR2 and TLR4 have been shown to recognize cryptococcal GXM (Shoham et al., 2001; Yauch et al., 2004, 2005). GXM was shown to bind to both TLR2 and TLR4 with the co-receptor CD14 but failed to activate the MAPK pathway and produce TNF- $\alpha$ (Shoham et al., 2001). TLR2 KO mice were more susceptible to cryptococcal infection than WT control mice; however, there was no difference in survival in $\mathrm{C} 3 \mathrm{H} / \mathrm{HeJ}$ mice which have a non-functional TLR4, compared to control mice (Yauch et al., 2004). Mice deficient in the adaptor molecule MyD88 (myeloid differentiation primary response gene 88 ), which is used by all TLRs except TLR3, exhibited a significant increase in mortality compared to WT mice and succumbed to a cryptococcal infection faster than the TLR2 KO mice, suggesting that MyD88 is required for protection against C. neoformans (Yauch et al., 2004; Biondo et al., 2005). Peritoneal macrophages from TLR2 KO or MyD88 KO mice exhibit reduced production of TNF- $\alpha$ when cultured with C. neoformans in vitro (Biondo et al., 2005). Furthermore, TLR2 KO and MyD88 KO mice showed decreased expression of TNF- $\alpha$, IFN- $\gamma$, and IL-12p40 transcripts in the lungs, brain, and spleen during infection with C. neoformans (Biondo et al., 2005). Peripheral blood mononuclear cells (PBMCs) isolated from patients with cryptococcal meningitis exhibited a significant reduction in TLR2 expression compared to healthy control PBMCs and blocking TLR2 on PBMCs led to a reduction in IL-12p70 and IFN- $\gamma$ when stimulated with Cryptococcus (Zhang et al., 2015a). While TLR2 and TLR4 can recognize cryptococcal GXM, these receptors may only play a minor role in protection to C. neoformans infection (Nakamura et al., 2006). What is clear is that MyD88 is necessary for protection against C. neoformans, suggesting that other TLRs are required.

TLR9 is an endosomal PRR that recognizes unmethylated pathogen $\mathrm{CPG}$ DNA following its ingestion and degradation by the immune cell. Uptake of $C$. neoformans leads to the recruitment of TLR9 to the fungal phagosome (Kasperkovitz et al., 2011), and TLR9 KO mice were more susceptible to cryptococcal infection than WT control mice (Wang et al., 2011). Mice treated with the TLR9 antagonist CpG-ODN 3 days before infection with $C$. neoformans strain 52D, a moderately virulent clinical isolate, had reduced fungal burden and pulmonary eosinophilia as well as increased IFN- $\gamma$ production by $\mathrm{CD}^{+}$ T cells (Edwards et al., 2005). Cryptococcal DNA can activate DCs via TLR9 recognition to produce IL-12p40 and express CD40 (Nakamura et al., 2008). This activity was dependent on the methylation of the DNA as methylase treatment of the DNA led to a reduction of IL-12p40 produced by the DCs. Genetic ablation of TLR9 or MyD88 completely abrogated the 


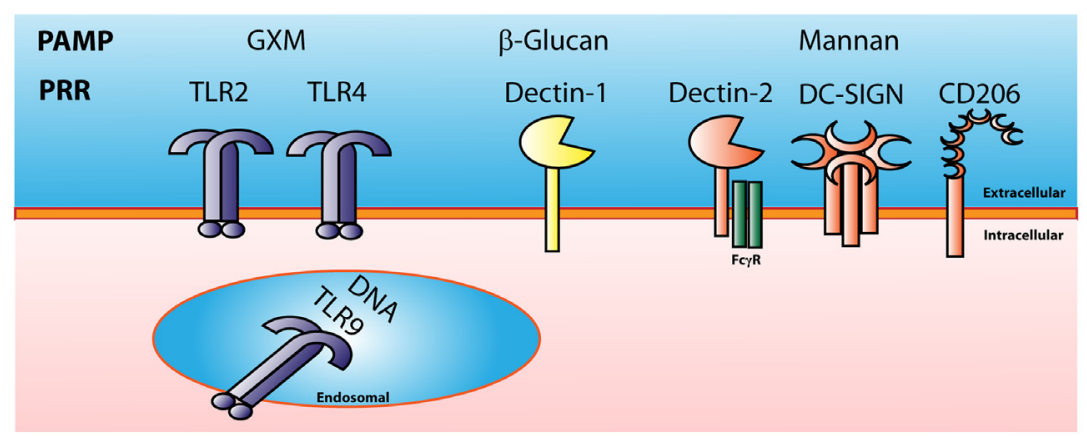

FIGURE 3 | Cryptococcal Pattern Recognition Receptors. Cryptococcus has multiple pathogen associated molecular patterns (PAMPs) that are recognized by many types of pattern recognition receptors (PRRs). GXM is recognized by TLR2 and TLR4. Cryptococcal mannan can be recognized by the C-type lectin receptors Dectin-2, DC-SIGN, and CD206 or mannose receptor. B-glucans found in the cryptococcal cell wall can be recognized by Dectin-1, and cryptococcal DNA can be recognized by the endosomal receptor TLR9.

effect of cryptococcal DNA on the DCs, demonstrating that DNA recognition and activation by DCs was dependent on TLR9 and MyD88 (Nakamura et al., 2008). Culture supernatants from C. neoformans are able to dampen the DC response to cryptococcal DNA (Yamamoto et al., 2011). The inhibitory effects of the supernatants were reduced by heat or trypsin treatment indicating that $C$. neoformans secretes proteinaceous molecules that suppress activation of DCs by cryptococcal DNA (Yamamoto et al., 2011). It was shown that the nucleic acid sequence for cryptococcal URA5 specifically activates DCs through a TLR9mediated signaling pathway using a mechanism that is different than the canonical CpG motif that is associated with TLR9 signaling (Tanaka et al., 2012). Cryptococcal infection in TLR9 KO mice leads to decreased IFN- $\gamma$ and TNF- $\alpha$ and an increase in IL-4 compared with WT mice (Zhang et al., 2010). The increased IL-4 in C. neoformans-infected TLR9 KO mice led to increased M2 macrophage activation markers arginase and FIZZ1 and a decrease in M1 macrophage marker iNOS compared to WT mice (Zhang et al., 2010). Ablation of TLR9 led to reduction of $\mathrm{CD}_{11} \mathrm{~b}^{+}$DCs and CCL7 in the lungs during the afferent phase (week 1) and reduced the pulmonary accumulation of CD11b ${ }^{+}$ DCs during the efferent phase [week 3; (Qiu et al., 2012)].

The fungal cell surface is covered in carbohydrates including $\beta$-glucans and mannan which are recognized by C-type lectin receptors (CLRs). The $\beta$-glucan CLR Dectin-1 has been shown to be important in protection to Aspergillus, Candida, and Pneumocystis infections (Steele et al., 2005; Saijo et al., 2007; Taylor et al., 2007). Dectin-1 has been shown to bind to the $\beta$-glucans found on cryptococcal spores (Giles et al., 2009), however, there was no significant difference in disease progression in Dectin-1 KO mice compared to WT mice during cryptococcal infection indicating that Dectin-1 may not be required for host defense to C. neoformans (Nakamura et al., 2007).

There are multiple receptors that recognize mannan including the CLRs Dectin-2, MR (CD206), and DC-SIGN. Dectin-2 has been shown to recognize mannan from multiple fungal organisms (Hardison and Brown, 2012). Dectin-2 KO BMDCs incubated with C. neoformans failed to produce IL-12p40 and
TNF- $\alpha$ as well as failed to increase surface expression of CD86 and MHC II compared to WT BMDCs (Nakamura et al., 2015). In addition, Dectin-2 KO mice infected with $C$. neoformans exhibited higher levels of Th2-type cytokines which are associated with non-protective immune responses compared to infected WT mice (Nakamura et al., 2015). Both MR and DC-SIGN have been shown to recognize heavily mannosylated cryptococcal mannoproteins (Mansour et al., 2006). Human and murine DCs are able to recognize and capture cryptococcal MPs by a mannose receptor (CD206) mediated process (Mansour et al., 2006). MR KO mice succumb to C. neoformans infection significantly faster compared to WT mice (Dan et al., 2008a). Cryptococcal MPs in combination with TLR ligands enhanced production of proinflammatory cytokines and chemokines from DCs as well as enhanced MP-specific MHC II-restricted CD4 ${ }^{+}$T-cell responses (Dan et al., 2008a). Increased surface expression of CD206, which is upregulated on M2 macrophages, results in increased phagocytosis but is accompanied by decreased intracellular killing and TNF- $\alpha$ production (Dan et al., 2008a).

\section{TARGETING MACROPHAGES AND DCS FOR VACCINES/IMMUNOTHERAPIES}

As demonstrated in the above discussion, innate phagocytes play a pivotal role in the recognition of Cryptococcus, antifungal activity, and prevention of cryptococcosis. Identification of the specific PRRs utilized by innate immune cells to recognize Cryptococcus and lead to the yeast's internalization and destruction could provide a novel target for treatment. Studies designed to elucidate the host PRR must keep in mind that different immune cells could utilize different PRRs to recognize Cryptococcus. In addition, the PAMPs for C. neoformans and C. gattii may not be the same. More study is required to identify the specific PAMP and PRR combination that elicits protective immune responses.

As C. gattii tends to cause disease in immunocompetent individuals, traditional methods of vaccination that elicit a memory $\mathrm{T}$ cell response could prove fruitful, however, this 
has not yet been achieved. High-risk groups for cryptococcosis caused by $C$. neoformans, including AIDS patients, are deficient in $\mathrm{CD}^{+} \mathrm{T}$ cells. Nonetheless, recent evidence does suggest that development of a vaccine against Cryptococcus is feasible (reviewed in Leopold Wager and Wormley, 2015). It has been shown that $\mathrm{CD}^{+} \mathrm{T}$ cells can compensate for the loss of $\mathrm{CD}^{+} \mathrm{T}$ cells (Lindell et al., 2005), thus targeting this adaptive immune cell population is possible. Interestingly, immunization of mice with the IFN- $\gamma$ producing C. neoformans strain $\mathrm{H} 99 \gamma$ leads to protection in B cell deficient mice (Wozniak et al., 2009) as well as WT BALB/c mice that are depleted of both $\mathrm{CD}^{+} / \mathrm{CD}^{+} \mathrm{T}$ cells during the challenge phase (Wozniak et al., 2011b), suggesting that protection can be achieved in the absence of traditional adaptive immunity. A relatively new concept allows for the generation of "innate memory" or "trained immunity." This memory occurs in innate cells, including NK cells and monocytes/macrophages in response to Candida albicans or simply by "training" via exposure to $\beta$-glucans (Quintin et al., 2012). The "trained" monocytes/macrophages have enhanced cytokine recall responses when challenged with C. albicans. The protective responses in these cells are nonspecific and confer heightened responses following secondary exposure to an antigen, including C. albicans. Altogether, this evidence is proof-of-concept that protection can be achieved in immunocompromised individuals.

A novel delivery platform utilizing glucan particles is a promising approach to vaccine design that targets innate phagocytes, including macrophages and DCs. The glucan particles are isolated from baker's yeast (Saccharomyces) and are purified, hollow, and porous cell wall shells composed mostly of $\beta$-1,3-glucan (reviewed in Levitz et al., 2015). These stimulate dectin-1 and other PRRs on phagocytes and induce the production of protective cytokines such as IFN- $\gamma$ and IL-17A (Huang et al., 2009, 2010, 2012, 2013; reviewed in Levitz et al., 2015). The glucan particles can be loaded with proteins, siRNA, DNA, and other small molecules. Immunization with these particles loaded with synthetic peptides of Coccidioides results in elevated Th1 and Th17 responses following challenge with Coccidioides posadasii (Hurtgen et al., 2012). A recently published study loaded the glucan particles with soluble alkaline extracts from two different attenuated Cryptococcus strains, acapsular strain cap59 and strain cda123 which lacks cell wall chitosan. Immunization of mice with the cryptococcal-loaded glucan particles resulted in increased survival following challenge with C. neoformans Kn99 and was associated with Th1 and Th17 immune responses (Specht et al., 2015). In addition, mice immunized with glucan particles loaded with cap59 extracts were partially protected against challenge with C. gattii strain R265 (Specht et al., 2015). Thus, these studies have identified novel vaccine candidates in the alkaline extracts from C. neoformans, and suggest that administration via this delivery system is promising for novel vaccine development.

Immunodominant cryptococcal proteins have recently been identified from both C. neoformans and C. gattii (Chaturvedi et al., 2013, 2014). Intranasal immunization of mice with cryptococcal cell wall and/or cytoplasmic protein fractions from C. gattii or immunodominant protein fractions from C. neoformans extended survival following challenge of the respective Cryptococcus sp (Chaturvedi et al., 2013, 2014). In addition, certain mannoproteins have been shown to elicit vaccine-mediate immunity, extending survival of C. neoformans infected mice (reviewed in Chaturvedi and Wormley, 2013; Levitz et al., 2015). PBMCs from patients who have recovered from cryptococcosis are able to proliferate and produce pro-inflammatory cytokines when stimulated with mannoproteins (Levitz and North, 1997). These proteins and other highly conserved antigens, including heat shock proteins, $\beta$-glucan, and glycolytic enzymes, are potential targets for the development of subunit vaccines. Vaccines that utilize recombinant proteins must take into account the posttranslational modifications of these cryptococcal proteins and how that affects immunogenicity.

Specific targeting of macrophage phenotype also has the potential for development of vaccines that would target the host and not the organism, thus limiting selective pressure on the fungus. Treatment of macrophages with IFN- $\gamma$ results in the M1, fungicidal phenotype, while stimulation with IL4/IL-13 results in the M2, cryptococcal growth-permissive phenotype (Olszewski et al., 2010; Leopold Wager and Wormley, 2014). It was recently demonstrated that macrophages first polarized to an M2 phenotype with IL-4 can be repolarized to an M1 phenotype following IFN- $\gamma$ treatment (Davis et al., 2013), demonstrating the plasticity of macrophages in response to their cytokine milieu. These repolarized macrophages are fully functional M1 macrophages, produce NO and are anticryptococcal (Davis et al., 2013). Additionally, immunization of mice with the $C$. neoformans IFN- $\gamma$-producing strain (H99 $\gamma$ ) and challenge with WT C. neoformans H99 results in complete protection and M1 macrophage activation (Hardison et al., 2012). This macrophage polarization is occurring even without exogenous IFN- $\gamma$ produced by the organism, providing evidence for memory $\mathrm{T}$ cell responses and possibly for "innate memory" in the macrophages. Recent studies have also shown that DCs are capable of polarizing to a proinflammatory DC1 phenotype and anti-inflammatory DC2 phenotype, which may also play a role in cryptococcal immune responses (Guiducci et al., 2005; Cook et al., 2012). Taken together, these studies suggest that targeting the polarization of macrophages and/or DCs toward an anti-cryptococcal phenotype could provide a novel mechanism for the induction of protective responses against Cryptococcus. Thus, these innate phagocytes that are critical for the development of protective responses against cryptococci could also be the key to development of novel vaccines and/or immunotherapies to prevent cryptococcosis.

\section{CONCLUSION}

The interactions between the host and the pathogen are critical for early control of the infection and, thus, the ability of the host to clear the infection. Cryptococcus has developed numerous effective strategies to either evade the immune system 
or to modulate the host cells allowing survival and replication within the phagocyte. There is still much to learn about how the host cells react to Cryptococcus and how they allow themselves to be manipulated by the fungus, as well as how the yeast expertly modulates and evades the immune system. In addition, there is an added complexity when the site of infection and the stage of disease is taken into account. Future research should aim to determine the roles of specific molecular interactions between Cryptococcus and phagocytes, and how these interactions either contribute to or prevent pathogenesis. A comprehensive understanding of these small, yet substantial interactions will undoubtedly result in effective anti-cryptococcal therapies that will likely be translatable to other intracellular infections which rely so desperately on the early responses of phagocytes.

\section{REFERENCES}

Aguirre, K. M., and Gibson, G. W. (2000). Differing requirement for inducible nitric oxide synthase activity in clearance of primary and secondary Cryptococcus neoformans infection. Med. Mycol. 38, 343-353. doi: 10.1080/mmy.38.5.343.353

Aguirre, K., Havell, E. A., Gibson, G. W., and Johnson, L. L. (1995). Role of tumor necrosis factor and gamma interferon in acquired resistance to Cryptococcus neoformans in the central nervous system of mice. Infect. Immun. 63, 1725-1731.

Almeida, F., Wolf, J. M., and Casadevall, A. (2015). Virulence-associated enzymes of Cryptococcus neoformans. Eukaryot. Cell 14, 1173-1185. doi: 10.1128/EC.00103-115

Alspaugh, J. A. (2015). Virulence mechanisms and Cryptococcus neoformans pathogenesis. Fungal Genet. Biol. 78, 55-58. doi: 10.1016/j.fgb.2014.09.004.

Alspaugh, J. A., and Granger, D. L. (1991). Inhibition of Cryptococcus neoformans replication by nitrogen oxides supports the role of these molecules as effectors of macrophage-mediated cytostasis. Infect. Immunol. 59, 2291-2296.

Alvarez, M., and Casadevall, A. (2006). Phagosome extrusion and host-cell survival after Cryptococcus neoformans phagocytosis by macrophages. Curr. Biol. 16, 2161-2165. doi: 10.1016/j.cub.2006.09.061

Angkasekwinai, P., Sringkarin, N., Supasorn, O., Fungkrajai, M., Wang, Y.-H., Chayakulkeeree, M., et al. (2014). Cryptococcus gattii Infection Dampens Th1 and Th17 responses by attenuating dendritic cell function and pulmonary chemokine expression in the immunocompetent hosts. Infect. Immunol. 82, 3880-3890. doi: 10.1128/iai.01773-1714

Aratani, Y., Kura, F., Watanabe, H., Akagawa, H., Takano, Y., Ishida-Okawara, A., et al. (2006). Contribution of the myeloperoxidase-dependent oxidative system to host defence against Cryptococcus neoformans. J. Med. Microbiol. 55, 1291-1299. doi: 10.1099/jmm.0.46620-46620

Arora, S., Hernandez, Y., Erb-Downward, J. R., McDonald, R. A., Toews, G. B., and Huffnagle, G. B. (2005). Role of IFN-gamma in regulating $\mathrm{T}_{2}$ immunity and the development of alternatively activated macrophages during allergic bronchopulmonary mycosis. J. Immunol. 174, 6346-6356. doi: 10.4049/jimmunol.174.10.6346

Arora, S., Olszewski, M. A., Tsang, T. M., McDonald, R. A., Toews, G. B., and Huffnagle, G. B. (2011). Effect of cytokine interplay on macrophage polarization during chronic pulmonary infection with Cryptococcus neoformans. Infect. Immun. 79, 1915-1926. doi: 10.1128/IAI.01270-1210

Artavanis-Tsakonas, K., Love, J. C., Ploegh, H. L., and Vyas, J. M. (2006). Recruitment of CD63 to Cryptococcus neoformans phagosomes requires acidification. Proc. Natl. Acad. Sci. U.S.A. 103, 15945-15950. doi: 10.1073/pnas.0607528103

Bauman, S. K., Huffnagle, G. B., and Murphy, J. W. (2003). Effects of tumor necrosis factor alpha on dendritic cell accumulation in lymph nodes draining the immunization site and the impact on the anticryptococcal cellmediated immune response. Infect. Immun. 71, 68-74. doi: 10.1128/IAI.71.1.6874.2003

\section{AUTHOR CONTRIBUTIONS}

$\mathrm{CW}, \mathrm{CH}, \mathrm{KW}$, and FW contributed to the writing, editing, and revision of the manuscript.

\section{ACKNOWLEDGMENTS}

Supported by research grant 2RO1AI071752 and R21AI100893 from the National Institute of Allergy and Infectious Diseases (NIAID) of the National Institutes of Health (NIH) and by Army Research Office of the Department of Defense No. W911NF11-1-0136 (FW). The funders had no role in study design, data collection and analysis, decision to publish, or preparation of the manuscript.

Bauman, S. K., Nichols, K. L., and Murphy, J. W. (2000). Dendritic cells in the induction of protective and nonprotective anticryptococcal cell-mediated immune responses. J. Immunol. 165, 158-167. doi: 10.4049/jimmunol.165. 1.158

Biondo, C., Midiri, A., Messina, L., Tomasello, F., Garufi, G., Catania, M. R., et al. (2005). MyD88 and TLR2, but not TLR4, are required for host defense against Cryptococcus neoformans. Eur. J. Immunol. 35, 870-878. doi: 10.1002/eji.200425799

Bogdan, C., Rollinghoff, M., and Diefenbach, A. (2000). Reactive oxygen and reactive nitrogen intermediates in innate and specific immunity. Curr. Opin. Immunol. 12, 64-76. doi: 10.1016/S0952-7915(99)00052-7

Chang, Y. C., Stins, M. F., McCaffery, M. J., Miller, G. F., Pare, D. R., Dam, T., et al. (2004). Cryptococcal yeast cells invade the central nervous system via transcellular penetration of the blood-brain barrier. Infect. Immun. 72, 4985-4995. doi: 10.1128/IAI.72.9.4985-4995.2004

Charlier, C., Chretien, F., Baudrimont, M., Mordelet, E., Lortholary, O., and Dromer, F. (2005). Capsule structure changes associated with Cryptococcus neoformans crossing of the blood-brain barrier. Am. J. Pathol. 166, 421-432. doi: 10.1016/S0002-9440(10)62265-62261

Chaturvedi, A. K., Hameed, R. S., Wozniak, K. L., Hole, C. R., Leopold Wager, C. M., Weintraub, S. T., et al. (2014). Vaccine-mediated immune responses to experimental pulmonary Cryptococcus gattii infection in mice. PLoS ONE 9:e104316. doi: 10.1371/journal.pone.0104316

Chaturvedi, A. K., Weintraub, S. T., Lopez-Ribot, J. L., and Wormley, F. L. Jr. (2013). Identification and Characterization of Cryptococcus neoformans protein fractions that induce protective immune responses. Proteomics 13, 3429-3441. doi: 10.1002/pmic.201300213

Chaturvedi, A. K., and Wormley, F. L. Jr. (2013). Cryptococcus antigens and immune responses: implications for a vaccine. Expert Rev. Vacc. 12, 1261-1272. doi: 10.1586/14760584.2013.840094

Chen, G. H., McNamara, D. A., Hernandez, Y., Huffnagle, G. B., Toews, G. B., and Olszewski, M. A. (2008). Inheritance of immune polarization patterns is linked to resistance versus susceptibility to Cryptococcus neoformans in a mouse model. Infect. Immun. 76, 2379-2391. doi: 10.1128/IAI. 01143-1147

Chen, S. H., Stins, M. F., Huang, S. H., Chen, Y. H., Kwon-Chung, K. J., Chang, Y., et al. (2003). Cryptococcus neoformans induces alterations in the cytoskeleton of human brain microvascular endothelial cells. J. Med. Microbiol. 52, 961-970. doi: 10.1099/jmm.0.05230-5230

Cheng, P. Y., Sham, A., and Kronstad, J. W. (2009). Cryptococcus gattii isolates from the British Columbia cryptococcosis outbreak induce less protective inflammation in a murine model of infection than Cryptococcus neoformans. Infect. Immun. 77, 4284-4294. doi: 10.1128/IAI.00628-629

Chinen, T., Qureshi, M. H., Koguchi, Y., and Kawakami, K. (1999). Candida albicans suppresses nitric oxide (NO) production by interferon-gamma (IFN-gamma) and lipopolysaccharide (LPS)-stimulated murine peritoneal macrophages. Clin. Exp. Immunol. 115, 491-497. doi: 10.1046/j.13652249.1999.00822.x 
Chretien, F., Lortholary, O., Kansau, I., Neuville, S., Gray, F., and Dromer, F. (2002). Pathogenesis of cerebral Cryptococcus neoformans infection after fungemia. J. Infect. Dis. 186, 522-530. doi: 10.1086/341564

Coelho, C., Souza, A. C., Derengowski Lda, S., de Leon-Rodriguez, C., Wang, B., Leon-Rivera, R., et al. (2015). Macrophage mitochondrial and stress response to ingestion of Cryptococcus neoformans. J. Immunol. 194, 2345-2357. doi: 10.4049/jimmunol.1402350

Coenjaerts, F. E. J., Walenkamp, A. M. E., Mwinzi, P. N., Scharringa, J., Dekker, H. A. T., van Strijp, J. A. G., et al. (2001). Potent inhibition of neutrophil migration by cryptococcal mannoprotein-4-induced desensitization. J. Immunol. 167, 3988-3995. doi: 10.4049/jimmunol.167. 7.3988

Cook, P. C., Jones, L. H., Jenkins, S. J., Wynn, T. A., Allen, J. E., and MacDonald, A. S. (2012). Alternatively activated dendritic cells regulate $\mathrm{CD}^{4+} \mathrm{T}$-cell polarization in vitro and in vivo. Proc. Natl. Acad. Sci. U.S.A. 109, 9977-9982. doi: $10.1073 /$ pnas. 1121231109

Dan, J. M., Kelly, R. M., Lee, C. K., and Levitz, S. M. (2008a). Role of the mannose receptor in a murine model of Cryptococcus neoformans infection. Infect. Immun. 76, 2362-2367. doi: 10.1128/IAI.00095-98

Dan, J. M., Wang, J. P., Lee, C. K., and Levitz, S. M. (2008b). Cooperative stimulation of dendritic cells by Cryptococcus neoformans mannoproteins and CpG oligodeoxynucleotides. PLOS ONE 3:e2046. doi: 10.1371/journal.pone.0002046

Davis, M. J., Eastman, A. J., Qiu, Y., Gregorka, B., Kozel, T. R., Osterholzer, J. J., et al. (2015). Cryptococcus neoformans-induced macrophage lysosome damage crucially contributes to fungal virulence. J. Immunol. 194, 2219-2231. doi: 10.4049/jimmunol.1402376

Davis, M. J., Tsang, T. M., Qiu, Y., Dayrit, J. K., Freij, J. B., Huffnagle, G. B., et al. (2013). Macrophage M1/M2 polarization dynamically adapts to changes in cytokine microenvironments in Cryptococcus neoformans infection. MBio 4:e00264-00213. doi: 10.1128/mBio.00264-213

Diamond, R. D., and Bennett, J. E. (1973). Growth of Cryptococcus neoformans within human macrophages in vitro. Infect. Immun. 7, 231-236.

Ding, A. H., Nathan, C. F., and Stuehr, D. J. (1988). Release of reactive nitrogen intermediates and reactive oxygen intermediates from mouse peritoneal macrophages. Comparison of activating cytokines and evidence for independent production. J. Immunol. 141, 2407-2412.

Djordjevic, J. T., Del Poeta, M., Sorrell, T. C., Turner, K. M., and Wright, L. C. (2005). Secretion of cryptococcal phospholipase B1 (PLB1) is regulated by a glycosylphosphatidylinositol (GPI) anchor. Biochem. J. 389, 803-812. doi: 10.1042/BJ20050063

Doering, T. L. (2009). How sweet it is! Cell wall biogenesis and polysaccharide capsule formation in Cryptococcus neoformans. Annu. Rev. Microbiol. 63, 223-247. doi: 10.1146/annurev.micro.62.081307.162753

Dong, Z. M., and Murphy, J. W. (1995). Effects of the two varieties of Cryptococcus neoformans cells and culture filtrate antigens on neutrophil locomotion. Infect. Immun. 63, 2632-2644.

Eastman, A. J., He, X., Qiu, Y., Davis, M. J., Vedula, P., Lyons, D. M., et al. (2015). Cryptococcal heat shock protein 70 homolog Ssal contributes to pulmonary expansion of Cryptococcus neoformans during the afferent phase of the immune response by promoting macrophage M2 polarization. J. Immunol. 194, 5999-6010. doi: 10.4049/jimmunol.1402719

Edwards, L., Williams, A. E., Krieg, A. M., Rae, A. J., Snelgrove, R. J., and Hussell, T. (2005). Stimulation via Toll-like receptor 9 reduces Cryptococcus neoformans-induced pulmonary inflammation in an IL-12-dependent manner. Eur. J. Immunol. 35, 273-281. doi: 10.1002/eji.200425640

Ellerbroek, P. M., Walenkamp, A. M., Hoepelman, A. I., and Coenjaerts, F. E. (2004). Effects of the capsular polysaccharides of Cryptococcus neoformans on phagocyte migration and inflammatory mediators. Curr. Med. Chem. 11, 253-266. doi: 10.2174/0929867043456188

Evans, R. J., Li, Z., Hughes, W. S., Djordjevic, J. T., Nielsen, K., and May, R. C. (2015). Cryptococcal phospholipase B1 is required for intracellular proliferation and control of titan cell morphology during macrophage infection. Infect. Immun. 83, 1296-1304. doi: 10.1128/IAI.03104-3114

Facchetti, F., Vermi, W., Fiorentini, S., Chilosi, M., Caruso, A., Duse, M., et al. (1999). Expression of inducible nitric oxide synthase in human granulomas and histiocytic reactions. Am. J. Pathol. 154, 145-152. doi: 10.1016/S00029440(10)65261-65263
Fels, A. O., and Cohn, Z. A. (1986). The alveolar macrophage. J. Appl. Physiol. 60, 353-369.

Giles, S. S., Dagenais, T. R., Botts, M. R., Keller, N. P., and Hull, C. M. (2009). Elucidating the pathogenesis of spores from the human fungal pathogen Cryptococcus neoformans. Infect. Immun. 77, 3491-3500. doi: 10.1128/IAI.00334-339

Grahnert, A., Richter, T., Piehler, D., Eschke, M., Schulze, B., Muller, U., et al. (2014). IL-4 receptor-alpha-dependent control of Cryptococcus neoformans in the early phase of pulmonary infection. PLOS ONE 9:e87341. doi: 10.1371/journal.pone.0087341

Gratchev, A., Kzhyshkowska, J., Kothe, K., Muller-Molinet, I., Kannookadan, S., Utikal, J., et al. (2006). Mphil and Mphi2 can be re-polarized by Th2 or Th1 cytokines, respectively, and respond to exogenous danger signals. Immunobiology 211, 473-486. doi: 10.1016/j.imbio.2006.05.017

Grijpstra, J., Tefsen, B., van Die, I., and de Cock, H. (2009). The Cryptococcus neoformans cap 10 and cap59 mutant strains, affected in glucuronoxylomannan synthesis, differentially activate human dendritic cells. FEMS Immunol. Med. Microbiol. 57, 142-150. doi: 10.1111/j.1574-695X.2009.00587.x

Gross, T. J., Kremens, K., Powers, L. S., Brink, B., Knutson, T., Domann, F. E., et al. (2014). Epigenetic silencing of the human $\mathrm{NOS}_{2}$ gene: rethinking the role of nitric oxide in human macrophage inflammatory responses. J. Immunol. 192, 2326-2338. doi: 10.4049/jimmunol.1301758

Guiducci, C., Vicari, A. P., Sangaletti, S., Trinchieri, G., and Colombo, M. P. (2005). Redirecting in vivo elicited tumor infiltrating macrophages and dendritic cells towards tumor rejection. Cancer Res. 65, 3437-3446. doi: 10.1158/00085472.CAN-04-4262

Hagen, F., Khayhan, K., Theelen, B., Kolecka, A., Polacheck, I., Sionov, E., et al. (2015). Recognition of seven species in the Cryptococcus gattii/Cryptococcus neoformans species complex. Fungal Genet. Biol. 78, 16-48. doi: 10.1016/j.fgb.2015.02.009

Hardison, S. E., and Brown, G. D. (2012). C-type lectin receptors orchestrate antifungal immunity. Nat. Immunol. 13, 817-822. doi: 10.1038/ni.2369

Hardison, S. E., Herrera, G., Young, M. L., Hole, C. R., Wozniak, K. L., et al. (2012). Protective immunity against pulmonary cryptococcosis is associated with STAT1-mediated classical macrophage activation. J. Immunol. 189, 4060-4068. doi: 10.4049/jimmunol.1103455

Hardison, S. E., Ravi, S., Wozniak, K. L., Young, M. L., Olszewski, M. A., and Wormley, F. L. Jr. (2010). Pulmonary infection with an interferongamma-producing Cryptococcus neoformans strain results in classical macrophage activation and protection. Am. J. Pathol. 176, 774-785. doi: 10.2353/ajpath.2010.090634

Hole, C. R., Bui, H., Wormley, F. L. Jr., and Wozniak, K. L. (2012). Mechanisms of dendritic cell lysosomal killing of Cryptococcus. Sci. Rep. 2:739. doi: 10.1038/srep00739

Hole, C. R., and Wormley, F. L. Jr. (2012). Vaccine and immunotherapeutic approaches for the prevention of cryptococcosis: lessons learned from animal models. Front. Microbiol. 3:291. doi: 10.3389/fmicb.2012.00291

Hu, X., Herrero, C., Li, W. P., Antoniv, T. T., Falck-Pedersen, E., Koch, A. E., et al. (2002). Sensitization of IFN-gamma Jak-STAT signaling during macrophage activation. Nat. Immunol. 3, 859-866. doi: 10.1038/ni828

Huang, H., Ostroff, G. R., Lee, C. K., Agarwal, S., Ram, S., Rice, P. A., et al. (2012). Relative contributions of dectin-1 and complement to immune responses to particulate $\beta$-glucans. J. Immunol. 189, 312-317. doi: 10.4049/jimmunol.1200603

Huang, H., Ostroff, G. R., Lee, C. K., Specht, C. A., and Levitz, S. M. (2010). Robust stimulation of humoral and cellular immune responses following vaccination with antigen-loaded beta-glucan particles. MBio 1, e00164-10. doi: 10.1128/mBio.00164-10

Huang, H., Ostroff, G. R., Lee, C. K., Specht, C. A., and Levitz, S. M. (2013). Characterization and optimization of the glucan particle-based vaccine platform. Clin. Vaccine Immunol. 20, 1585-1591. doi: 10.1128/CVI.00463-13

Huang, H., Ostroff, G. R., Lee, C. K., Wang, J. P., Specht, C. A., and Levitz, S. M. (2009). Distinct patterns of dendritic cell cytokine release stimulated by fungal $\beta$-glucans and toll-like receptor agonists. Infect. Immun. 77, 1774-1781. doi: 10.1128/IAI.00086-09

Huffnagle, G. B. (1996). Role of cytokines in T cell immunity to a pulmonary Cryptococcus neoformans infection. Biol. Signals 5, 215-222. doi: $10.1159 / 000109193$ 
Huffnagle, G. B., Boyd, M. B., Street, N. E., and Lipscomb, M. F. (1998). IL-5 is required for eosinophil recruitment, crystal deposition, and mononuclear cell recruitment during a pulmonary Cryptococcus neoformans infection in genetically susceptible mice (C57BL/6). J. Immunol. 160, 2393-2400.

Huffnagle, G. B., and Lipscomb, M. F. (1998). Cells and cytokines in pulmonary cryptococcosis. Res. Immunol. 149, 387-396; discussion 512-384. doi: 10.1016/s0923-2494(98)80762-1

Huffnagle, G. B., Yates, J. L., and Lipscomb, M. F. (1991). Immunity to a Pulmonary Cryptococcus neoformans infection requires both $\mathrm{Cd} 4^{+}$and $\mathrm{Cd} 8^{+}$T-Cells. J. Exp. Med. 173, 793-800. doi: 10.1084/jem.173.4.793

Hurtgen, B. J., Hung, C. Y., Ostroff, G. R., Levitz, S. M., and Cole, G. T. (2012). Construction and evaluation of a novel recombinant $\mathrm{T}$ cell epitopebased vaccine against Coccidioidomycosis. Infect. Immun. 80, 3960-3974. doi: 10.1128/IAI.00566-512

Husain, S., Wagener, M. M., and Singh, N. (2001). Cryptococcus neoformans infection in organ transplant recipients: variables influencing clinical characteristics and outcome. Emerg. Infect. Dis. 7, 375-381. doi: 10.3201/eid0703.010302

Hussell, T., and Bell, T. J. (2014). Alveolar macrophages: plasticity in a tissuespecific context. Nat. Rev. Immunol. 14, 81-93. doi: 10.1038/nri3600

Huston, S. M., Li, S. S., Stack, D., Timm-McCann, M., Jones, G. J., Islam, A., et al. (2013). Cryptococcus gattii is killed by dendritic cells, but evades adaptive immunity by failing to induce dendritic cell maturation. J. Immunol. 191, 249-261. doi: 10.4049/jimmunol.1202707

Ibrahim, A. S., Filler, S. G., Alcouloumre, M. S., Kozel, T. R., Edwards, J. E. Jr., and Ghannoum, M. A. (1995). Adherence to and damage of endothelial cells by Cryptococcus neoformans in vitro: role of the capsule. Infect. Immun. 63, 4368-4374.

Jain, A. V., Zhang, Y., Fields, W. B., McNamara, D. A., Choe, M. Y., Chen, G. H., et al. (2009). Th2 but not Th1 immune bias results in altered lung functions in a murine model of pulmonary Cryptococcus neoformans infection. Infect. Immun. 77, 5389-5399. doi: 10.1128/IAI.00809-809

Johnston, S. A., and May, R. C. (2010). The human fungal pathogen Cryptococcus neoformans escapes macrophages by a phagosome emptying mechanism that is inhibited by Arp2/3 complex-mediated actin polymerisation. PLoS Pathog 6:e1001041. doi: 10.1371/journal.ppat.1001041

Johnston, S. A., and May, R. C. (2013). Cryptococcus interactions with macrophages: evasion and manipulation of the phagosome by a fungal pathogen. Cell Microbiol. 15, 403-411. doi: 10.1111/cmi.12067

Kasperkovitz, P. V., Khan, N. S., Tam, J. M., Mansour, M. K., Davids, P. J., and Vyas, J. M. (2011). Toll-like receptor 9 modulates macrophage antifungal effector function during innate recognition of Candida albicans and Saccharomyces cerevisiae. Infect. Immun. 79, 4858-4867. doi: 10.1128/IAI.05626-5611

Kavanaugh, L. A., Fraser, J. A., and Dietrich, F. S. (2006). Recent evolution of the human pathogen Cryptococcus neoformans by intervarietal transfer of a 14-gene fragment. Mol. Biol. Evol. 23, 1879-1890. doi: 10.1093/molbev/msl070

Kawakami, K., Qureshi, M. H., Zhang, T., Okamura, H., Kurimoto, M., and Saito, A. (1997a). IL-18 protects mice against pulmonary and disseminated infection with Cryptococcus neoformans by inducing IFN-gamma production. J. Immunol. 159, 5528-5534.

Kawakami, K., Zhang, T., Qureshi, M. H., and Saito, A. (1997b). Cryptococcus neoformans inhibits nitric oxide production by murine peritoneal macrophages stimulated with interferon-gamma and lipopolysaccharide. Cell Immunol. 180, 47-54. doi: 10.1006/cimm.1997.1166

Kawakami, K., Tohyama, M., Xie, Q., and Saito, A. (1996). IL-12 protects mice against pulmonary and disseminated infection caused by Cryptococcus neoformans. Clin. Exp. Immunol. 104, 208-214. doi: 10.1046/j.1365-2249.1996.14723.x

Kelly, R. M., Chen, J. M., Yauch, L. E., and Levitz, S. M. (2005). Opsonic requirements for dendritic cell-mediated responses to Cryptococcus neoformans. Infect. Immunol. 73, 592-598. doi: 10.1128/IAI.73.1.592-598.2005

Kleinschek, M. A., Muller, U., Schutze, N., Sabat, R., Straubinger, R. K., Blumenschein, W. M., et al. (2010). Administration of IL-23 engages innate and adaptive immune mechanisms during fungal infection. Int. Immunol. 22, 81-90. doi: 10.1093/intimm/dxp117

Korn, T., Bettelli, E., Oukka, M., and Kuchroo, V. K. (2009). IL-17 and Th17 Cells. Annu. Rev. Immunol. 27, 485-517. doi: 10.1146/annurev.immunol.021908.132710
Korn, T., Oukka, M., Kuchroo, V., and Bettelli, E. (2007). Th17 cells: effector $\mathrm{T}$ cells with inflammatory properties. Semin. Immunol. 19, 362-371. doi: 10.1016/j.smim.2007.10.007

Kozel, T. R. (1993). Opsonization and phagocytosis of Cryptococcus neoformans. Arch. Med. Res. 24, 211-218.

Kronstad, J. W., Attarian, R., Cadieux, B., Choi, J., D’Souza, C. A., Griffiths, E. J., et al. (2011). Expanding fungal pathogenesis: Cryptococcus breaks out of the opportunistic box. Nat. Rev. Microbiol. 9, 193-203. doi: 10.1038/nrmicro 2522

Kwon-Chung, K. J., Fraser, J. A., Doering, T. L., Wang, Z., Janbon, G., Idnurm, A., et al. (2014). Cryptococcus neoformans and Cryptococcus gattii, the etiologic agents of cryptococcosis. Cold Spring Harb Perspect. Med. 4:a019760. doi: 10.1101/cshperspect.a019760

Kwon-Chung, K., and Saijo, T. (2015). Is Cryptococcus gattii a primary pathogen? J. Fungi 1:154. doi: 10.3390/jof1020154

Leopold Wager, C. M., Hole, C. R., Wozniak, K. L., Olszewski, M. A., Mueller, M., and Wormley, F. L. Jr. (2015). STAT1 signaling within macrophages is required for anti-fungal activity against Cryptococcus neoformans. Infect. Immun. 83, 4513-4527. doi: 10.1128/IAI.00935-915

Leopold Wager, C. M., Hole, C. R., Wozniak, K. L., Olszewski, M. A., and Wormley, F. L. Jr. (2014). STAT1 signaling is essential for protection against Cryptococcus neoformans infection in mice. J. Immunol. 193, 4060-4071. doi: 10.4049/jimmunol.1400318

Leopold Wager, C. M., and Wormley, F. L. (2014). Classical versus alternative macrophage activation: the Ying and the Yang in host defense against pulmonary fungal infections. Mucosal Immunol. 7, 1023-1035. doi: 10.1038/mi.2014.65

Leopold Wager, C. M., and Wormley, F. L. Jr. (2015). Is development of a vaccine against Cryptococcus neoformans feasible? PLoS Pathog. 11:e1004843. doi: 10.1371/journal.ppat.1004843

Levitz, S. M., Huang, H., Ostroff, G. R., and Specht, C. A. (2015). Exploiting fungal cell wall components in vaccines. Semin. Immunopathol. 37, 199-207. doi: 10.1007/s00281-014-0460-466

Levitz, S. M., Nong, S. H., Seetoo, K. F., Harrison, T. S., Speizer, R. A., and Simons, E. R. (1999). Cryptococcus neoformans resides in an acidic phagolysosome of human macrophages. Infect. Immun. 67, 885-890.

Levitz, S. M., and North, E. A. (1997). Lymphoproliferation and cytokine profiles in human peripheral blood mononuclear cells stimulated by Cryptococcus neoformans. J. Med. Vet. Mycol. 35, 229-236. doi: 10.1080/02681219780001201

Lindell, D. M., Moore, T. A., McDonald, R. A., Toews, G. B., and Huffnagle, G. B. (2005). Generation of antifungal effector $\mathrm{CD} 8^{+} \mathrm{T}$ cells in the absence of $\mathrm{CD} 4^{+}$ T cells during Cryptococcus neoformans infection. J. Immunol. 174, 7920-7928. doi: 10.4049/jimmunol.174.12.7920

Liu, L., Tewari, R. P., and Williamson, P. R. (1999). Laccase protects Cryptococcus neoformans from antifungal activity of alveolar macrophages. Infect. Immun. 67, 6034-6039.

Liu, T. B., Perlin, D. S., and Xue, C. (2012). Molecular mechanisms of cryptococcal meningitis. Virulence 3, 173-181. doi: 10.4161/viru.18685

Liu, T. B., and Xue, C. (2014). Fbp1-mediated ubiquitin-proteasome pathway controls Cryptococcus neoformans virulence by regulating fungal intracellular growth in macrophages. Infect. Immun. 82, 557-568. doi: 10.1128/IAI.00 994-913

Lizarazo, J., Escandon, P., Agudelo, C. I., Firacative, C., Meyer, W., and Castaneda, E. (2014). Retrospective study of the epidemiology and clinical manifestations of Cryptococcus gattii infections in Colombia from 1997-2011. PLoS Negl. Trop. Dis. 8:e3272. doi: 10.1371/journal.pntd.0003272

Lupo, P., Chang, Y. C., Kelsall, B. L., Farber, J. M., Pietrella, D., Vecchiarelli, A., et al. (2008). The presence of capsule in Cryptococcus neoformans influences the gene expression profile in dendritic cells during interaction with the fungus. Infect. Immunol. 76, 1581-1589. doi: 10.1128/IAI.01184-1187

Mambula, S. S., Simons, E. R., Hastey, R., Selsted, M. E., and Levitz, S. M. (2000). Human neutrophil-mediated nonoxidative antifungal activity against Cryptococcus neoformans. Infect. Immunol. 68, 6257-6264. doi: 10.1128/IAI.68.11.6257-6264.2000

Mansour, M. K., Latz, E., and Levitz, S. M. (2006). Cryptococcus neoformans glycoantigens are captured by multiple lectin receptors and presented by dendritic cells. J. Immunol. 176, 3053-3061. doi: 10.4049/jimmunol.176. 5.3053 
Mansour, M. K., Schlesinger, L. S., and Levitz, S. M. (2002). Optimal T cell responses to Cryptococcus neoformans mannoprotein are dependent on recognition of conjugated carbohydrates by mannose receptors. J. Immunol. 168, 2872-2879. doi: 10.4049/jimmunol.168.6.2872

Mantovani, A., Biswas, S. K., Galdiero, M. R., Sica, A., and Locati, M. (2013). Macrophage plasticity and polarization in tissue repair and remodelling. J. Pathol. 229, 176-185. doi: 10.1002/path.4133

Mantovani, A., Sica, A., Sozzani, S., Allavena, P., Vecchi, A., and Locati, M. (2004). The chemokine system in diverse forms of macrophage activation and polarization. Trends Immunol. 25, 677-686. doi: 10.1016/j.it.2004. 09.015

Marr, K. A., Datta, K., Pirofski, L. A., and Barnes, R. (2012). Cryptococcus gattii infection in healthy hosts: a sentinel for subclinical immunodeficiency? Clin. Infect. Dis. 54, 153-154. doi: 10.1093/cid/cir756

Martinez, F. O., Helming, L., and Gordon, S. (2009). Alternative activation of macrophages: an immunologic functional perspective. Annu. Rev. Immunol. 27, 451-483. doi: 10.1146/annurev.immunol.021908.132532

Mattila, J. T., Ojo, O. O., Kepka-Lenhart, D., Marino, S., Kim, J. H., Eum, S. Y., et al. (2013). Microenvironments in tuberculous granulomas are delineated by distinct populations of macrophage subsets and expression of nitric oxide synthase and arginase isoforms. J. Immunol. 191, 773-784. doi: 10.4049/jimmunol.1300113

Mednick, A. J., Feldmesser, M., Rivera, J., and Casadevall, A. (2003). Neutropenia alters lung cytokine production in mice and reduces their susceptibility to pulmonary cryptococcosis. Eur. J. Immunol. 33, 1744-1753. doi: $10.1002 /$ eji.200323626

Milam, J. E., Herring-Palmer, A. C., Pandrangi, R., McDonald, R. A., Huffnagle, G. B., and Toews, G. B. (2007). Modulation of the pulmonary type 2 T-cell response to Cryptococcus neoformans by intratracheal delivery of a tumor necrosis factor alpha-expressing adenoviral vector. Infect. Immunol. 75, 4951-4958. doi: 10.1128/IAI.00176-177

Mosser, D. M., and Edwards, J. P. (2008). Exploring the full spectrum of macrophage activation. Nat. Rev. Immunol. 8, 958-969. doi: 10.1038/nri2448

Muller, U., Stenzel, W., Kohler, G., Werner, C., Polte, T., Hansen, G., et al. (2007). IL-13 induces disease-promoting type 2 cytokines, alternatively activated macrophages and allergic inflammation during pulmonary infection of mice with Cryptococcus neoformans. J. Immunol. 179, 5367-5377. doi: 10.4049/jimmunol.179.8.5367

Murdock, B. J., Teitz-Tennenbaum, S., Chen, G. H., Dils, A. J., Malachowski, A. N., Curtis, J. L., et al. (2014). Early or late IL-10 blockade enhances Th1 and th17 effector responses and promotes fungal clearance in mice with cryptococcal lung infection. J. Immunol. 193, 4107-4116. doi: 10.4049/jimmunol.1400650

Murray, P. J., and Wynn, T. A. (2011). Protective and pathogenic functions of macrophage subsets. Nat. Rev. Immunol. 11, 723-737. doi: 10.1038/Nri3073

Nakamura, K., Kinjo, T., Saijo, S., Miyazato, A., Adachi, Y., Ohno, N., et al. (2007). Dectin-1 is not required for the host defense to Cryptococcus neoformans. Microbiol. Immunol. 51, 1115-1119. doi: 10.1111/j.1348-0421.2007.tb04007.x

Nakamura, K., Miyagi, K., Koguchi, Y., Kinjo, Y., Uezu, K., Kinjo, T., et al. (2006). Limited contribution of Toll-like receptor 2 and 4 to the host response to a fungal infectious pathogen, Cryptococcus neoformans. FEMS Immunol. Med. Microbiol. 47, 148-154. doi: 10.1111/j.1574-695X.2006.00078.x

Nakamura, K., Miyazato, A., Xiao, G., Hatta, M., Inden, K., Aoyagi, T., et al. (2008). Deoxynucleic acids from Cryptococcus neoformans activate myeloid dendritic cells via a TLR9-dependent pathway. J. Immunol. 180, 4067-4074. doi: 10.4049/jimmunol.180.6.4067

Nakamura, Y., Sato, K., Yamamoto, H., Matsumura, K., Matsumoto, I., Nomura, T., et al. (2015). Dectin-2 deficiency promotes Th2 response and mucin production in the lungs after pulmonary infection with Cryptococcus neoformans. Infect. Immun. 83, 671-681. doi: 10.1128/IAI.02835-2814

Naslund, P. K., Miller, W. C., and Granger, D. L. (1995). Cryptococcus neoformans fails to induce nitric oxide synthase in primed murine macrophage-like cells. Infect. Immun. 63, 1298-1304.

Ngamskulrungroj, P., Chang, Y., Sionov, E., and Kwon-Chung, K. J. (2012). The primary target organ of Cryptococcus gattii is different from that of Cryptococcus neoformans in a murine model. MBio 3:e00103-e00112. doi: 10.1128/mBio.00103-112

Nicola, A. M., Robertson, E. J., Albuquerque, P., Derengowski Lda, S., and Casadevall, A. (2011). Nonlytic exocytosis of Cryptococcus neoformans from macrophages occurs in vivo and is influenced by phagosomal pH. MBio 2:e00167-e00211. doi: 10.1128/mBio.001 67-111

Okagaki, L. H., and Nielsen, K. (2012). Titan cells confer protection from phagocytosis in Cryptococcus neoformans infections. Eukaryot. Cell 11, 820-826. doi: 10.1128/EC.00121-112

Okagaki, L. H., Strain, A. K., Nielsen, J. N., Charlier, C., Baltes, N. J., Chretien, F., et al. (2010). Cryptococcal cell morphology affects host cell interactions and pathogenicity. PLoS Pathog. 6:e1000953. doi: 10.1371/journal.ppat.10 00953

Olszewski, M. A., Noverr, M. C., Chen, G. H., Toews, G. B., Cox, G. M., Perfect, J. R., et al. (2004). Urease expression by Cryptococcus neoformans promotes microvascular sequestration, thereby enhancing central nervous system invasion. Am. J. Pathol. 164, 1761-1771. doi: 10.1016/S0002-9440(10)6373463730

Olszewski, M. A., Zhang, Y., and Huffnagle, G. B. (2010). Mechanisms of cryptococcal virulence and persistence. Future Microbiol. 5, 1269-1288. doi: $10.2217 / \mathrm{fmb} .10 .93$

O'Meara, T. R., and Alspaugh, J. A. (2012). The Cryptococcus neoformans capsule: a sword and a shield. Clin. Microbiol. Rev. 25, 387-408. doi: 10.1128/CMR.0 0001-12

Onishi, R. M., and Gaffen, S. L. (2010). Interleukin-17 and its target genes: mechanisms of interleukin-17 function in disease. Immunology 129, 311-321. doi: 10.1111/j.1365-2567.2009.03240.x

Osterholzer, J. J., Curtis, J. L., Polak, T., Ames, T., Chen, G.-H., McDonald, R., et al. (2008). $\mathrm{CCR}_{2}$ mediates conventional dendritic cell recruitment and the formation of bronchovascular mononuclear cell infiltrates in the lungs of mice infected with Cryptococcus neoformans. J. Immunol. 181, 610-620. doi: 10.4049/jimmunol.181.1.610

Osterholzer, J. J., Milam, J. E., Chen, G. H., Toews, G. B., Huffnagle, G. B., and Olszewski, M. A. (2009a). Role of dendritic cells and alveolar macrophages in regulating early host defense against pulmonary infection with Cryptococcus neoformans. Infect. Immun. 77, 3749-3758. doi: 10.1128/IAI.00 454-459

Osterholzer, J. J., Surana, R., Milam, J. E., Montano, G. T., Chen, G. H., Sonstein, J., et al. (2009b). Cryptococcal urease promotes the accumulation of immature dendritic cells and a non-protective $\mathrm{T}_{2}$ immune response within the lung. Am. J. Pathol. 174, 932-943. doi: 10.2353/ajpath.2009.080673

Panackal, A. A., Wuest, S. C., Lin, Y. C., Wu, T., Zhang, N., Kosa, P., et al. (2015). Paradoxical immune responses in non-HIV cryptococcal meningitis. PLoS Pathog. 11:e1004884. doi: 10.1371/journal.ppat.10 04884

Panepinto, J. C., and Williamson, P. R. (2006). Intersection of fungal fitness and virulence in Cryptococcus neoformans. FEMS Yeast Res. 6, 489-498. doi: 10.1111/j.1567-1364.2006.00078.x

Park, S. J., and Mehrad, B. (2009). Innate immunity to Aspergillus species. Clin. Microbiol. Rev. 22, 535-551. doi: 10.1128/CMR.00014-19

Pietrella, D., Corbucci, C., Perito, S., Bistoni, G., and Vecchiarelli, A. (2005). Mannoproteins from Cryptococcus neoformans promote dendritic cell maturation and activation. Infect. Immunol. 73, 820-827. doi: 10.1128/IAI.73.2.820-827.2005

Porcheray, F., Viaud, S., Rimaniol, A. C., Leone, C., Samah, B., DereuddreBosquet, N., et al. (2005). Macrophage activation switching: an asset for the resolution of inflammation. Clin. Exp. Immunol. 142, 481-489. doi: 10.1111/j.1365-2249.2005.02934.x

Powderly, W. G. (1993). Cryptococcal meningitis and AIDS. Clin. Infect. Dis. 17, 837-842. doi: 10.1093/clinids/17.5.837

Qiu, Y., Zeltzer, S., Zhang, Y., Wang, F., Chen, G. H., Dayrit, J., et al. (2012). Early induction of CCL7 downstream of TLR9 signaling promotes the development of robust immunity to cryptococcal infection. J. Immunol. 188, 3940-3948. doi: 10.4049/jimmunol.1103053

Quintin, J., Saeed, S., Martens, J. H., Giamarellos-Bourboulis, E. J., Ifrim, D. C., Logie, C., et al. (2012). Candida albicans infection affords protection against reinfection via functional reprogramming of monocytes. Cell Host Microbe 12, 223-232. doi: 10.1016/j.chom.2012.06.006

Qureshi, A., Grey, A., Rose, K. L., Schey, K. L., and Del Poeta, M. (2011). Cryptococcus neoformans modulates extracellular killing by neutrophils. Front. Microbiol. 2:193. doi: 10.3389/fmicb.2011.00193 
Qureshi, A., Subathra, M., Grey, A., Schey, K., Del Poeta, M., and Luberto, C. (2010). Role of sphingomyelin synthase in controlling the antimicrobial activity of neutrophils against Cryptococcus neoformans. PLoS ONE 5:e15587. doi: 10.1371/journal.pone.0015587

Reese, T. A., Liang, H. E., Tager, A. M., Luster, A. D., Van Rooijen, N., Voehringer, D., et al. (2007). Chitin induces accumulation in tissue of innate immune cells associated with allergy. Nature 447, 92-96. doi: $10.1038 /$ nature 05746

Rivera, J., Mukherjee, J., Weiss, L. M., and Casadevall, A. (2002). Antibody efficacy in murine pulmonary Cryptococcus neoformans infection: a role for nitric oxide. J. Immunol. 168, 3419-3427. doi: 10.4049/jimmunol.168.7.3419

Rocha, J. D., Nascimento, M. T., Decote-Ricardo, D., Corte-Real, S., Morrot, A., Heise, N., et al. (2015). Capsular polysaccharides from Cryptococcus neoformans modulate production of neutrophil extracellular traps (NETs) by human neutrophils. Sci. Rep. 5:8008. doi: 10.1038/srep08008

Saag, M. S., Graybill, R. J., Larsen, R. A., Pappas, P. G., Perfect, J. R., Powderly, W. G., et al. (2000). Practice guidelines for the management of cryptococcal disease. Infect. Dis. Soc. Am. Clin. Infect. Dis. 30, 710-718. doi: 10.1086/313757

Sabiiti, W., and May, R. C. (2012). Capsule independent uptake of the fungal pathogen Cryptococcus neoformans into brain microvascular endothelial cells. PLoS ONE 7:e35455. doi: 10.1371/journal.pone.0035455

Sabiiti, W., Robertson, E., Beale, M. A., Johnston, S. A., Brouwer, A. E., Loyse, A., et al. (2014). Efficient phagocytosis and laccase activity affect the outcome of HIV-associated cryptococcosis. J. Clin. Invest. 124, 2000-2008. doi: 10.1172/JCI72950

Saijo, S., Fujikado, N., Furuta, T., Chung, S. H., Kotaki, H., Seki, K., et al. (2007). Dectin-1 is required for host defense against Pneumocystis carinii but not against Candida albicans. Nat. Immunol. 8, 39-46. doi: 10.1038/ni1425

Saijo, T., Chen, J., Chen, S. C., Rosen, L. B., Yi, J., Sorrell, T. C., et al. (2014). Antigranulocyte-macrophage colony-stimulating factor autoantibodies are a risk factor for central nervous system infection by Cryptococcus gattii in otherwise immunocompetent patients. MBio 5:e00912-00914. doi: 10.1128/mBio.00 912-914

Shoham, S., Huang, C., Chen, J. M., Golenbock, D. T., and Levitz, S. M. (2001). Tolllike receptor 4 mediates intracellular signaling without TNF-alpha release in response to Cryptococcus neoformans polysaccharide capsule. J. Immunol. 166, 4620-4626. doi: 10.4049/jimmunol.166.7.4620

Sica, A., and Mantovani, A. (2012). Macrophage plasticity and polarization: in vivo veritas. J. Clin. Invest. 122, 787-795. doi: 10.1172/JCI59643

Smith, L. M., Dixon, E. F., and May, R. C. (2015). The fungal pathogen Cryptococcus neoformans manipulates macrophage phagosome maturation. Cell Microbiol. 17, 702-713. doi: 10.1111/cmi.12394

Sorrell, T. C., Juillard, P. G., Djordjevic, J. T., Kaufman-Francis, K., Dietmann, A., Milonig, A., et al. (2015). Cryptococcal transmigration across a model brain blood-barrier: evidence of the Trojan horse mechanism and differences between Cryptococcus neoformans var. grubii strain H99 and Cryptococcus gattii strain R265. Microbes Infect. 18, 57-67. doi: 10.1016/j.micinf.2015.08.017

Specht, C. A., Lee, C. K., Huang, H., Tipper, D. J., Shen, Z. T., Lodge, J. K., et al. (2015). Protection against experimental cryptococcosis following vaccination with glucan particles containing Cryptococcus alkaline extracts. MBio 6:e01905e01915. doi: 10.1128/mBio.01905-1915

Springer, D. J., Ren, P., Raina, R., Dong, Y., Behr, M. J., McEwen, B. F., et al. (2010). Extracellular fibrils of pathogenic yeast Cryptococcus gattii are important for ecological niche, murine virulence and human neutrophil interactions. PLoS ONE 5:e10978. doi: 10.1371/journal.pone.0010978

Steele, C., Rapaka, R. R., Metz, A., Pop, S. M., Williams, D. L., Gordon, S., et al. (2005). The beta-glucan receptor dectin-1 recognizes specific morphologies of Aspergillus fumigatus. PLoS Pathog 1:e42. doi: 10.1371/journal.ppat.0010042

Stein, M., Keshav, S., Harris, N., and Gordon, S. (1992). Interleukin 4 potently enhances murine macrophage mannose receptor activity: a marker of alternative immunologic macrophage activation. J. Exp. Med. 176, 287-292. doi: 10.1084/jem.176.1.287

Stenzel, W., Muller, U., Kohler, G., Heppner, F. L., Blessing, M., McKenzie, A. N., et al. (2009). IL-4/IL-13-dependent alternative activation of macrophages but not microglial cells is associated with uncontrolled cerebral cryptococcosis. Am. J. Pathol. 174, 486-496. doi: 10.2353/ajpath.2009.080598

Stout, R. D., Jiang, C., Matta, B., Tietzel, I., Watkins, S. K., and Suttles, J. (2005). Macrophages sequentially change their functional phenotype in response to changes in microenvironmental influences. J. Immunol. 175, 342-349. doi: 10.4049/jimmunol.175.1.342

Stout, R. D., and Suttles, J. (2004). Functional plasticity of macrophages: reversible adaptation to changing microenvironments. J. Leukoc. Biol. 76, 509-513. doi: 10.1189/jlb.0504272

Sun, D., Zhang, M., Liu, G., Wu, H., Zhu, X., Zhou, H., et al. (2016). Realtime imaging of interactions of neutrophils with Cryptococcus neoformans demonstrates a crucial role of complement C5a-C5aR signaling. Infect. Immun. 84, 216-229. doi: 10.1128/iai.01197-15

Syme, R. M., Spurrell, J. C. L., Amankwah, E. K., Green, F. H. Y., and Mody, C. H. (2002). Primary dendritic cells phagocytose Cryptococcus neoformans via mannose receptors and $\mathrm{Fc}$ gamma receptor II for presentation to $\mathrm{T}$ lymphocytes. Infect. Immun. 70, 5972-5981. doi: 10.1128/IAI.70.11.59725981.2002

Takeda, K., Kamanaka, M., Tanaka, T., Kishimoto, T., and Akira, S. (1996). Impaired IL-13-mediated functions of macrophages in STAT6-deficient mice. J. Immunol. 157, 3220-3222.

Tanaka, M., Ishii, K., Nakamura, Y., Miyazato, A., Maki, A., Abe, Y., et al. (2012). Toll-like receptor 9-dependent activation of bone marrow-derived dendritic cells by URA5 DNA from Cryptococcus neoformans. Infect. Immun. 80, 778-786. doi: 10.1128/IAI.05570-5511

Taylor, P. R., Tsoni, S. V., Willment, J. A., Dennehy, K. M., Rosas, M., Findon, H., et al. (2007). Dectin-1 is required for beta-glucan recognition and control of fungal infection. Nat. Immunol. 8, 31-38. doi: 10.1038/ni1408

Tucker, S. C., and Casadevall, A. (2002). Replication of Cryptococcus neoformans in macrophages is accompanied by phagosomal permeabilization and accumulation of vesicles containing polysaccharide in the cytoplasm. Proc. Natl. Acad. Sci. U.S.A. 99, 3165-3170. doi: 10.1073/pnas.0527 02799

Ueno, K., Kinjo, Y., Okubo, Y., Aki, K., Urai, M., Kaneko, Y., et al. (2015). Dendritic cell-based immunization ameliorates pulmonary infection with highly virulent Cryptococcus gattii. Infect. Immun. 83, 1577-1586. doi: 10.1128/iai.0 2827-2814

Urban, C. F., Lourido, S., and Zychlinsky, A. (2006). How do microbes evade neutrophil killing? Cell. Microbiol. 8, 1687-1696. doi: 10.1111/j.14625822.2006.00792.x

van der Horst, C. M., Saag, M. S., Cloud, G. A., Hamill, R. J., Graybill, J. R., Sobel, J. D., et al. (1997). Treatment of cryptococcal meningitis associated with the acquired immunodeficiency syndrome. National Institute of Allergy and Infectious Diseases Mycoses Study Group and AIDS Clinical Trials Group. N. Engl. J. Med. 337, 15-21. doi: 10.1056/NEJM1997070333 70103

Van Dyken, S. J., and Locksley, R. M. (2013). Interleukin-4- and interleukin-13mediated alternatively activated macrophages: roles in homeostasis and disease. Annu. Rev. Immunol. 31, 317-343. doi: 10.1146/annurev-immunol-032712095906

Van Dyken, S. J., Mohapatra, A., Nussbaum, J. C., Molofsky, A. B., Thornton, E. E., Ziegler, S. F., et al. (2014). Chitin activates parallel immune modules that direct distinct inflammatory responses via innate lymphoid type 2 and gamma/delta T cells. Immunity 40, 414-424. doi: 10.1016/j.immuni.2014.02.003

Vecchiarelli, A., Pietrella, D., Lupo, P., Bistoni, F., McFadden, D. C., and Casadevall, A. (2003). The polysaccharide capsule of Cryptococcus neoformans interferes with human dendritic cell maturation and activation. J. Leukoc. Biol. 74, 370-378. doi: 10.1189/jlb.1002476

Voelz, K., Johnston, S. A., Smith, L. M., Hall, R. A., Idnurm, A., and May, R. C. (2014). 'Division of labour' in response to host oxidative burst drives a fatal Cryptococcus gattii outbreak. Nat. Commun. 5:5194. doi: 10.1038/ncomms6194

Voelz, K., Lammas, D. A., and May, R. C. (2009). Cytokine signaling regulates the outcome of intracellular macrophage parasitism by Cryptococcus neoformans. Infect. Immun. 77, 3450-3457. doi: 10.1128/IAI.00297-299

$\mathrm{Vu}$, K., Bautos, J. M., and Gelli, A. (2015). The Cch1-Mid1 high-affinity calcium channel contributes to the virulence of Cryptococcus neoformans by mitigating oxidative stress. Eukaryot. Cell 14, 1135-1143. doi: 10.1128/EC.0 0100-115

Vu, K., Tham, R., Uhrig, J. P., Thompson, G. R. III, Na Pombejra, S., Jamklang, M., et al. (2014). Invasion of the central nervous system by Cryptococcus neoformans requires a secreted fungal metalloprotease. MBio 5:e01101-01114. doi: 10.1128/mBio.01101-1114 
Walker, J. A., Barlow, J. L., and McKenzie, A. N. (2013). Innate lymphoid cells-how did we miss them? Nat. Rev. Immunol. 13, 75-87. doi: 10.1038/nri3349

Walker, J. A., and McKenzie, A. N. (2013). Development and function of group 2 innate lymphoid cells. Curr. Opin. Immunol. 25, 148-155. doi: 10.1016/j.coi.2013.02.010

Wang, J. P., Lee, C. K., Akalin, A., Finberg, R. W., and Levitz, S. M. (2011). Contributions of the MyD88-dependent receptors IL-18R, IL-1R, and TLR9 to host defenses following pulmonary challenge with Cryptococcus neoformans. PLoS ONE 6:e26232. doi: 10.1371/journal.pone.0026232

Wiesner, D. L., Specht, C. A., Lee, C. K., Smith, K. D., Mukaremera, L., Lee, S. T., et al. (2015). Chitin recognition via chitotriosidase promotes pathologic type2 helper T cell responses to cryptococcal infection. PLoS Pathog. 11:e1004701. doi: 10.1371/journal.ppat.1004701

Wormley, F. L. Jr., Perfect, J. R., Steele, C., and Cox, G. M. (2007). Protection against cryptococcosis by using a murine gamma interferonproducing Cryptococcus neoformans strain. Infect. Immun. 75, 1453-1462. doi: 10.1128/IAI.00274-276

Wozniak, K. L., Hardison, S. E., Kolls, J. K., and Wormley, F. L. (2011a). Role of IL17A on resolution of pulmonary C. neoformans infection. PLoS ONE 6:e17204. doi: 10.1371/journal.pone.0017204

Wozniak, K. L., Young, M. L., and Wormley, F. L. Jr. (2011b). Protective immunity against experimental pulmonary cryptococcosis in T cell-depleted mice. Clin. Vacc. Immunol. 18, 717-723. doi: 10.1128/CVI.00036-11

Wozniak, K. L., Kolls, J. K., and Wormley, F. L. Jr. (2012). Depletion of neutrophils in a protective model of pulmonary cryptococcosis results in increased IL-17A production by gamma/delta T cells. BMC Immunol. 13:65. doi: 10.1186/14712172-13-65

Wozniak, K. L., and Levitz, S. M. (2008). Cryptococcus neoformans enters the endolysosomal pathway of dendritic cells and is killed by lysosomal components. Infect. Immun. 76, 4764-4771. doi: 10.1128/IAI. 00660-08

Wozniak, K. L., Ravi, S., Macias, S., Young, M. L., Olszewski, M. A., Steele, C., et al. (2009). Insights into the mechanisms of protective immunity against Cryptococcus neoformans infection using a mouse model of pulmonary cryptococcosis. PLoS ONE 4:e6854. doi: 10.1371/journal.pone.0 006854

Wozniak, K. L., Vyas, J. M., and Levitz, S. M. (2006). In vivo role of dendritic cells in a murine model of pulmonary cryptococcosis. Infect. Immun. 74, 3817-3824. doi: 10.1128/iai.00317-06

Wright, L., Bubb, W., Davidson, J., Santangelo, R., Krockenberger, M., Himmelreich, U., et al. (2002). Metabolites released by Cryptococcus neoformans var. neoformans and var. gattii differentially affect human neutrophil function. Microbes Infect. 4, 1427-1438. doi: 10.1016/S1286-4579(02)00 024-2

Xiao, G., Miyazato, A., Inden, K., Nakamura, K., Shiratori, K., Nakagawa, K., et al. (2008). Cryptococcus neoformans inhibits nitric oxide synthesis caused by CpG-oligodeoxynucleotide-stimulated macrophages in a fashion independent of capsular polysaccharides. Microbiol. Immunol. 52, 171-179. doi: 10.1111/j.1348-0421.2008.00019.x

Yamamoto, H., Abe, Y., Miyazato, A., Tanno, D., Tanaka, M., Miyasaka, T., et al. (2011). Cryptococcus neoformans suppresses the activation of bone marrowderived dendritic cells stimulated with its own DNA, but not with DNA from other fungi. FEMS Immunol. Med. Microbiol. 63, 363-372. doi: 10.1111/j.1574695X.2011.00859.x

Yauch, L. E., Lam, J. S., and Levitz, S. M. (2006). Direct inhibition of T-cell responses by the Cryptococcus capsular polysaccharide glucuronoxylomannan. PLoS Pathog. 2:e120. doi: 10.1371/journal.ppat.0020120
Yauch, L. E., Mansour, M. K., and Levitz, S. M. (2005). Receptor-mediated clearance of Cryptococcus neoformans capsular polysaccharide in vivo. Infect. Immunol. 73, 8429-8432. doi: 10.1128/IAI.73.12.8429-8432.2005

Yauch, L. E., Mansour, M. K., Shoham, S., Rottman, J. B., and Levitz, S. M. (2004). Involvement of CD14, toll-like receptors 2 and 4, and MyD88 in the host response to the fungal pathogen Cryptococcus neoformans in vivo. Infect. Immunol. 72, 5373-5382. doi: 10.1128/IAI.72.9.5373-5382.2004

Zaragoza, O., Chrisman, C. J., Castelli, M. V., Frases, S., Cuenca-Estrella, M., Rodriguez-Tudela, J. L., et al. (2008). Capsule enlargement in Cryptococcus neoformans confers resistance to oxidative stress suggesting a mechanism for intracellular survival. Cell Microbiol. 10, 2043-2057. doi: 10.1111/j.14625822.2008.01186.x

Zaragoza, O., Garcia-Rodas, R., Nosanchuk, J. D., Cuenca-Estrella, M., Rodriguez-Tudela, J. L., and Casadevall, A. (2010). Fungal cell gigantism during mammalian infection. PLoS Pathog. 6:e1000945. doi: 10.1371/journal.ppat.1000945

Zaragoza, O., Rodrigues, M. L., De Jesus, M., Frases, S., Dadachova, E., and Casadevall, A. (2009). The capsule of the fungal pathogen Cryptococcus neoformans. Adv. Appl. Microbiol. 68, 133-216. doi: 10.1016/S0065-2164(09)01204-1200

Zhang, L., Liu, T., Kong, W., Zhang, W., Gu, M., Chen, Y., et al. (2015a). Decreased $\mathrm{TLR}_{2}$ signal expression in peripheral blood mononuclear cell from patients with cryptococcal meningitis. Microbiol. Immunol. 59, 357-364. doi: 10.1111/1348-0421.12264

Zhang, M., Sun, D., Liu, G., Wu, H., Zhou, H., and Shi, M. (2015b). Real-time in vivo imaging reveals the ability of neutrophils to remove Cryptococcus neoformans directly from the brain vasculature. J. Leukocyte Biol. doi: 10.1189/jlb.4AB0715-281R

Zhang, T., Kawakami, K., Qureshi, M. H., Okamura, H., Kurimoto, M., and Saito, A. (1997). Interleukin-12 (IL-12) and IL-18 synergistically induce the fungicidal activity of murine peritoneal exudate cells against Cryptococcus neoformans through production of gamma interferon by natural killer cells. Infect. Immunol. 65, 3594-3599.

Zhang, Y., Wang, F., Bhan, U., Huffnagle, G. B., Toews, G. B., Standiford, T. J., et al. (2010). TLR9 signaling is required for generation of the adaptive immune protection in Cryptococcus neoformans-infected lungs. Am. J. Pathol. 177, 754-765. doi: 10.2353/ajpath.2010.091104

Zhang, Y., Wang, F., Tompkins, K. C., McNamara, A., Jain, A. V., Moore, B. B., et al. (2009). Robust Th1 and Th17 immunity supports pulmonary clearance but cannot prevent systemic dissemination of highly virulent Cryptococcus neoformans H99. Am. J. Pathol. 175, 2489-2500. doi: 10.2353/ajpath.2009.090530

Zhu, X., and Williamson, P. R. (2004). Role of laccase in the biology and virulence of Cryptococcus neoformans. FEMS Yeast Res. 5, 1-10. doi: 10.1016/j.femsyr.2004.04.004

Conflict of Interest Statement: The authors declare that the research was conducted in the absence of any commercial or financial relationships that could be construed as a potential conflict of interest.

Copyright (c) 2016 Leopold Wager, Hole, Wozniak and Wormley. This is an openaccess article distributed under the terms of the Creative Commons Attribution License (CC BY). The use, distribution or reproduction in other forums is permitted, provided the original author(s) or licensor are credited and that the original publication in this journal is cited, in accordance with accepted academic practice. No use, distribution or reproduction is permitted which does not comply with these terms. 